\title{
Integration of Airway Inflammation and Remodeling Mechanisms Specific to Eosinophilic Asthma Through Differential Co-Expression of Genes in Bronchial Brush Biopsy Samples
}

Pawel Kozlik

Jagiellonian University

Sylwia Buregwa-Czuma

Rzeszów University

Izabela Zawlik

Rzeszów University

Aleksander Myszka

Rzeszów University

Joanna Zuk

Jagiellonian University

Andzelika Siwiec

Jagiellonian University

Jacek Zarychta

Jagiellonian University

Krzysztof Okon

Jagiellonian University

Lech Zareba

Rzeszów University

Jerzy Soja

Jagiellonian University

Michal Kepski

Rzeszów University

Jan G. Bazan

Rzeszów University

Stanislawa Bazan-Socha ( $\nabla$ mmsocha@cyf-kr.edu.pl )

Jagiellonian University

Research Article

Keywords: inflammation, eosinophilic, bronchial 
Posted Date: February 24th, 2021

DOl: https://doi.org/10.21203/rs.3.rs-228649/v1

License: @ (i) This work is licensed under a Creative Commons Attribution 4.0 International License. Read Full License 


\section{Abstract \\ Background}

Heterogeneity of asthma complicates search for targeted treatment against airway hyperresponsiveness and remodeling. We conducted a systems biology approach study to establish differential co-expression of genes (DCG) in eosinophilic and non-eosinophilic asthma patients and infer their role in the disease.

\section{Materials and Methods}

$\mathrm{N}=40$ Caucasian adult moderate to severe non-smoking asthma patients (half with eosinophilic asthma) undergone bronchial brush biopsy sampling for mRNA expression using hybridization to CDNA microarray. Mechanistic interpretation of DCG was inferred from existing literature.

\section{Results}

Differentially co-expressed genes bear significance in airway viral infection (ATP1B1, EPS15), arachidonic acid metabolism (CLC, FADS6), cell migration (EPS8L1, STOML3, RhoBTB2), surface receptors endocytosis (STRN4, EPS15, ATP1B1) or decreased expression (CCT7), oxidative stress (DIO3, RhoBTB2), decreased adhesion (ATP1B1, RAPH1, STOML3), epithelial-mesenchymal transition (ASB3, RADX, CCT7, MRPL14, PPP2R3B, RPS13, SLC19A1), myofibroblast differentiation (CCT7), smooth muscle proliferation (ASB3, ATP1B1), airway hyperreactivity (RECK, STOML3, ATP1B1, OR5211), extracellular matrix remodeling (FBN3, RECK), angiogenesis (GPI, RhoBTB2) and neuronal pathogenesis of asthma (OR5211, STRN4, TTC3P1, GPI, CABP5) and were linked to asthma in genome- (MRPL14, ASB3, RPS13) and epigenome-wide (CLC, EPS15, GPI, SSCRB4, STRN4) association studies. Signaling pathways involved (especially TGF- $\beta / \mathrm{Smad} 2 / 3$ ) are inferred from the co-expression pattern.

\section{Conclusion}

Activity of genes and pathways of known or tentative role in asthma pathogenesis was established in regard to a condition cognizable in clinical practice.

\section{Introduction.}

Asthma is a prevalent chronic inflammatory disease of the airways with variable etiology, mechanistic pathways involved (i.e. endotype), clinicopathological presentation (i.e. phenotype), severity, reaction to treatment and prognosis. Quarter of all asthma patients and half of those with severe asthma develop progressive and irreversible airway obstruction, leading to persistent symptoms despite the exhaustion of therapeutic measures. Such course of the disease is attributed to airway remodeling, a process of structural changes of bronchi including loss of epithelial apical-to-basolateral polarity, epithelial sheathing, 
subepithelial fibrosis, epithelial-mesenchymal and fibroblast-to-myofibroblast transition, hyperplasia of smooth muscle and goblet cells, neovascularization and cartilage degeneration ${ }^{1}$, leading to hyperresponsiveness and persistent airflow limitation. Current treatment options have limited influence on remodeling and do not target it directly as mechanisms underlying the process are still investigated ${ }^{23}$. Since no accurate biomarker or clinical predictor of ongoing remodeling was agreed upon to date, there are no methods of selecting patients who could benefit the most from future experimental e.g. biological therapies before the process becomes clinically symptomatic or apparent in imaging studies ${ }^{4}$.

As eosinophilic asthma (EA) accounts for approximately half of the severe disease cases $^{5}$, search for therapeutic targets behind airway inflammation and remodeling specific to this phenotype presents an important scientific challenge.

In the present hypothesis-generating study we utilized systems biology approach to identify genes with coordinated expression in the airways of EA and non-EA patients, established networks of their binary interactions and regulation using curated resources and conducted a systematic review of the relevant literature to infer their possible role in the disease pathogenesis in search for novel regulators, biomarkers and mechanisms of airway inflammation and remodeling.

\section{Materials And Methods.}

\subsection{Patient selection}

The study included 40 non-smoking patients aged 20-70 years with at least 10-year history of asthma diagnosed by a physician in accordance with Global Initiative for Asthma (GINA) 2018 guidelines. The exclusion criteria were pregnancy or breastfeeding, any acute illness, history of congestive heart failure, atrial fibrillation (paroxysmal or persistent), myocardial infarction or stroke, neoplastic disease (past or current), thyroid disease, liver injury and chronic kidney disease (stage 3 or above) and smoking. Past smokers who stopped smoking at least 5 years before and accumulated less than 7 pack-years were permitted in the study. Asthma medications, except for biological treatment, were permitted, with oral corticosteroids at a daily dose $\leq 10 \mathrm{mg}$ of prednisolone equivalent unless the doses were unchanged during the preceding 3 months.

Half of the subjects $(\mathrm{N}=20)$ were diagnosed with eosinophilic asthma defined as having at least $1 \%$ of eosinophils in bronchoalveolar lavage fluid (BALF), thus comprised the EA group. The remaining individuals formed the non-eosinophilic asthma (non-EA) group $(\mathrm{N}=20)$.

\subsection{Spirometry studies}

Spirometry with bronchial reversibility test using $400 \mathrm{mg}$ of albuterol and body plethysmography after bronchodilator with assessment of the residual volume (RV) and total lung capacity (TLC) were carried out to assess differences in lung function between eosinophilic and non-EA patients using a Jaeger MasterLab spirometer (Jaeger-Toennies GmbH; Hochberg, Germany). 


\subsection{Lung computed tomography (CT) with evaluation of the airway cross-sectional geometry and percent of low attenuation area (LAA\%)}

CT indices of bronchial remodeling (parameters of airway cross-sectional geometry) and air trapping (LAA\%) were measured to compare EA and non-EA patients. Chest CT scans was performed 1 hour after administration of $400 \mathrm{mg}$ albuterol using 64-raw multidetector computed tomography (Aquilion TSX-101A, Toshiba Medical Systems Corporation, Otawara, Japan) in a helical scanning mode (CT parameters: $64 \mathrm{x}$ $0.5 \mathrm{~mm}$ collimation, helical pitch of 53 and 0.5 second per rotation with standard radiation dose [150 \pm 50 mAs and $120 \mathrm{kVp}$ ). Automated program AW Server (General Electric Healthcare, Wauwatosa, WI, USA) was used to quantify the airway cross-sectional geometry in four different bronchi: the RB1, the right lower lobe basal posterior bronchus (RB10), the left apicoposterior bronchus $(L B 1+2)$ and the left lower posterior basal bronchus (LB10). Scans were obtained with patients in the supine position at maximal inspiration with their arms held over their heads. Airway-geometry parameters were measured using methods previously described ${ }^{4}$. The LAA\% was quantified automatically using the Volume Viewer 11.3 software (General Electric Healthcare, Wauwatosa, WI, USA) with $1 \mathrm{~mm}$ soft tissue reconstruction algorithm.

\subsection{Bronchofiberoscopy}

Bronchofiberoscopy was performed according to the guidelines of the American Thoracic Society ${ }^{6}$ using the bronchofiberoscope BF 1 T180 (Olympus, USA) with local anesthesia ( $2 \%$ lidocaine) and in mild sedation (0.05-0.1 mg fentanyl and 2.5-5 mg midazolam, both intravenously). Brochoalverolar lavage (BAL) was performed with $200 \mathrm{ml}$ of $0.9 \%$ saline given to the right middle lobe bronchus and 2-3 bronchial brush biopsy (BBB) specimens were taken from the right lower lobe (the carina between B9 and B10). First $10 \mathrm{ml}$ of the obtained BAL fluid (BALF) was discarded.

\subsection{RNA acquisition.}

Total RNA was extracted from BBB samples with TRIzol ${ }^{\circledR}$, fractioned in gravity gradient, isolated in chromatographic columns and stored at $-80^{\circ} \mathrm{C}$. The quality of each sample was assessed using Qiagen ${ }^{\circledR}$ QIAxel and RNA integrity was verified using agarose gel electrophoresis. The resulting RNA was reversetranscribed into cDNA library using Syngen ${ }^{\circledR}$ UniversalScript Reverse Transcriptase. The product was purified by Syngen $\circledast$ PCR ME Mini Kit and fluorescently labeled and purified using Kreatech $\circledast$ ULS Platinum Bright Red/Orange Kit. Hybridization to microarrays occurred on the Human Genomic 49K Mi ReadyArray (a Human Exonic Evidence Based Oligonucleotide array [HEEBO]; Microarray Inc., Huntsville, $\mathrm{AL}, \mathrm{USA})$ at $37^{\circ} \mathrm{C}$ for $24 \mathrm{~h}$, subsequently washed.

\subsection{Laboratory investigations}

Fasting blood samples were drawn from the antecubital vein using minimal stasis between 8:00 and 11:00 A.M. into serum tubes and centrifuged, similarly to BALF at 2,000 g for 20 minutes. The supernatant was frozen in aliquots and stored at $-70^{\circ} \mathrm{C}$ until analysis. 
Immunoenzymatic assay (ELISA) was used to measure serum and BALF levels of interleukin (IL)-4, IL-5, IL6, IL-10, IL-12p70, IL-17A, IL-23 and interferon gamma (INF-y) (eBiosciencea, Vienna, Austria), serum periostin (Phoenix Pharmaceuticals, Burlingame, CA, USA) and serum disintegrin and metalloproteinase domain-containing protein 33 (ADAM 33) (Cloud-Clone Corp., Katy, TX, USA).

Basic statistical analysis was conducted using Statsoft ${ }^{\circledR}$ Statistica, v. 10.

\subsection{Microarray data retrieval.}

Microarrays were scanned with a InnoScan 900 Microarray Scanner and hybridization signals were detected using Mapix software (v.6.0.1; Innopsys, Carbonne, France).

The software failed to perform microarray gridding correctly in some cases. Since gridding is crucial for image analysis as an error occurring during this process may be propagated to further stages ${ }^{7}$, a custom gridding algorithm to avoid grid displacement was developed. The coordinates of positioning markers to establish sub-grids were found using an $\mathrm{MSER}^{8}$-based method. Computed results were verified manually and corrected if needed, with overall gridding performance exceeding that of the commercial software, ultimately resulting in expression profiles of 33519 gene products. Microarray data preprocessing (background correction and normalization) was done by limma R software using the established methods ${ }^{9,10}$. Genomic data were analyzed with Bioconductor v.3.7. software of the R environment v.3.5.0.

\subsection{Differential gene expression and co-expression identification and analysis.}

A list of differentially expressed genes (DEGs) was established using limma package to assess for possible confounding with differential co-expression ${ }^{11}$; false discovery rate (FDR) was assessed with Benjamini and Hochberg procedure. A list of differentially co-expressed genes (DCGs) was established using CoXpress ${ }^{12} \mathrm{R}$ plugin. In this method, groups of genes which expression levels are highly correlated in one set of experiments (i.e. EA), but not significantly correlated in a second set of experiments (i.e. non-EA) are found. A summary statistic of gene expression correlation matrix is made for each sample group and compared to distributions of $n=1000$ similar summary statistics generated by selecting groups of random genes of the same size from the same data set. The summary statistic used is the t-statistic taken from a test of the unique, pairwise, Pearson correlation coefficients against zero. The proportions of random statistics above the observed statistic are used to create a "probability of randomness" for each group in the two sample groups. A group of genes which distribution of pairwise correlations is found to be random in non-EA $(p \geq 0.05)$, and non-random in EA $(p<0.05)$, is said to be differentially co-expressed between the two groups.

\subsection{Gene set enrichment, creation of interaction networks and their topological robustness analysis.}

Associations between DCGs, airway inflammation and remodeling were investigated using the following workflow:

1. Gene set enrichment analysis (GSEA) was performed to establish histone modifications and cell types matching DCGs' expression pattern as well as associated biological processes, molecular functions 
and signaling pathways. The analysis was performed using Enrichr tool ${ }^{13}$ using curated datasets (Tab. 1).

2. Based on curated resources (1), we established (1) lung-specific binary protein-protein interactions of DCGs, (2) DCGs' upstream regulators and (3) DCG-microRNA-transcription factor interactions. Semiautomated analytics platforms Cytoscape 3.7.1 and NetworkAnalyst 3.0 were used to construct interaction networks as undirected graphs, where individual molecular entities formed the nodes and their interactions the edges.

3. Topological robustness analysis of the resulting graphs was performed by the previously described principle of topological attack on biological network ${ }^{14}$. Betweenness centrality was used to identify nodes with highest network-disruptive potential as possible targets for pharmacological interventions.

4. Betweenness centrality of the nodes was plotted against MEDLINE literature coverage using the keyword "asthma" to identify already established and candidate molecular entities of potential relevance. GenClip 3.0 sofware was used for automated literature mining.

5. Both individual DCGs and their first-degree interactors were investigated in an attempt at mechanistic explanation of their role in the disease by literature mining using the keyword "asthma" and either of allergy and airway inflammation-related or airway remodeling-related keywords:

(1) allergy and airway inflammation: Th1, Th2, Th17, dendritic cell, antigen-presenting, granulocyte, neutrophil, eosinophil, basophil, mastocyte, mast cell, monocyte, macrophage, lymphocyte, inflammation, thromboxane, prostaglandin, leukotriene, oxidative stress, allergy, allergic, atopy

(1) bronchial remodeling: airway, remodeling, epithelium, sheathing, basal lamina, basement membrane, extracellular matrix, subepithelial, fibrosis, fibroblast, myofibroblast, epithelial-mesenchymal, smooth muscle, goblet, mucus, neovascularization, cartilage, hyperresponsiveness, hypertrophy, mucus, cilia, cilium.

\subsection{Funding.}

This study was funded by the National Science Centre based on decision No. DEC-2013/09/B/NZ5/00758.

\subsection{Bioethics committee approval.}

The study was approved by the Ethics Committee of the Jagiellonian University (Skawinska 8 Str, 31-066 Krakow, Poland; phone number +48 1243327 39, e-mail: komisja_bioetyczna@cm-uj.krakow.pl) under approval number KBET/151/B/2013 and conducted in accordance with the Declaration of Helsinki. All participants gave written informed consent to participate in the study.

\section{Results And Discussion.}

\subsection{Sample description.}


Demographic, clinical and laboratory characteristics of the study subjects are provided in Tables 2-4. EA and non-EA patients were comparable regarding most demographic and clinical features except for $\mathrm{BMI}$, which was higher in the latter.

While the studied groups did not differ significantly in regard to lung function parameters, EA patients had more prominent absolute indices of airflow limitation (lower forced expiratory volume in 1 second; FEV ${ }_{1}$ ) and more favorable obstruction reversibility (higher DFEV $_{1}$ ), while non-EA patients had lower total lung capacity (TLC), possibly due to overrepresentation of obese subjects in this group. HRCT indices of airway remodeling were significantly more prominent in the EA group, consistent with the differences in lung function, suggesting computed tomography as superior to spirometry in detecting advancement of airway remodeling.

\subsection{Identification and study of differentially expressed genes.}

After background correction, quantile normalization and filtration for coefficients of gene expression variation between 0.3 and 10,14823 annotated gene products were included in subsequent analyses. Expression levels of 20 genes differed significantly between EA and non-EA by unadjusted $p$-value. According to automated literature mining, at least one of them was described in the context of asthma alone in one paper, three in the context of inflammation-related keywords over 8 papers and 9 in the context of remodeling-related keywords over 80 papers (Tab. 5, Fig. 1).

After adjustment for false discovery rate, no gene's expression level was found to significantly differ between EA and non-EA, concluding DEG analysis and indicating unconfounded pure differential coexpression discovery ${ }^{11}$.

\subsection{Identification and study of differentially co-expressed genes.}

Hierarchical cluster analysis revealed a total of 23 groups of DCGs. A single group consisting of 32 genes with the highest mean, pairwise difference between the correlation matrices of gene expressions in the two asthma groups was chosen for subsequent analyses (Tab. 6).

Only 5 of the 32 genes co-occurred with asthma over 9 papers, 6 with allergy/inflammation-related keywords over 98 papers and 15 with remodeling-related keywords over 133 papers (Fig. 2). Abundance of significant correlations between DCGs' expression levels within EA group may indicate its pathogenetic consistency, contrary to less correlated DCGs in the non-EA group (Fig. 3). The resulting list of candidate genes as well as their interactors and regulatory networks (Fig. 4-6) which may differentiate airway inflammation and remodeling mechanisms specific to EA and non-EA are discussed.

\subsection{Gene set enrichment analysis (GSEA) of DCGs.}

None of the DCGs were significantly enriched for ontology terms at adjusted p-value (false discovery rate) < 0.05 , expectedly, given the small gene set size. The results were ranked based on combined p-value and zscore. 


\subsubsection{Cell type-specific histone modifications related to expression of DCGs.}

Fifteen of the 32 DCGs (all up-regulated in the EA) matched differential expression pattern related to histone modifications H3K9ac and H3K27me3 of human lung fibroblast hg19, suggesting them as the likely source of the gene expression signal (Tab. 7). H3K9ac and H3K27me3 are the two histone modifications of dominant and opposite role in regulation of neuroectodermal differentiation ( $\mathrm{H} 3 \mathrm{~K} 9 \mathrm{ac})$ or pluripotency (H3K27me3) ${ }^{15}$. With H3K27me3 previously linked to epithelial-mesenchymal transition (EMT) and extracellular matrix degradation upon treatment of cell culture with TNF-a and TGF-b ${ }^{16}$, up-regulation of the genes related to both histone modifications in our study could indicate their role in ongoing EMT in EA, consistent with the abundance of eosinophil-derived TGF-b1 in this disease phenotype ${ }^{17}$.

\subsubsection{Gene ontology associations.}

Molecular functions and biological processes associated with DCGs by gene ontology are listed in Tab. 89. They include phenomena significant in the pathogenesis of asthma and airway remodeling, such as Tcell receptor binding, $\mathrm{MHC}$ II protein complex binding, immunoglobulin secretion, myeloid cell apoptosis, regulation of cellular response to growth factors (e.g. TGF-b) and metalloendopeptidase inhibitory activity, as further discussed in section 3.5.

\subsubsection{Kinase perturbation studies.}

Kinase perturbation studies included in Gene Expression Omnibus (GEO) database indicate differential expression of several DCGs upon knockout of the following kinases (Tab. 10):

(1)TGF-b receptor II (TGFBR2): down-regulation of CCT7, EPS15, MRPL14;

(2)Homeodomain-interacting protein kinase 1 (HIPK1): down-regulation of GPI, MAEA, STRN4;

(3) Inhibitor of nuclear factor kappa-B kinase subunit epsilon (IKBKE): up-regulation of DGLUCY, RAPH1, ASB3.

These kinase-dependent DCGs might indicated differential activity of the related pathways and have pathogenetic role in EA. The ligand of TGFBR2, TGF-b, has well-established role in asthma and airway remodeling, as further discussed in section 3.5, while the receptor itself was found to be involved in T-cell differentiation. The role of HIPK1 was to date only described in fetal angiogenesis activated by TGF- $\beta$ -

TAK1 pathway ${ }^{18}$, apoptosis induced by TNF-a and prevention of MAP3K5-JNK activation. Our study links HIPK1 with eosinophilic asthma through the pattern of DCGs, a suggestion reinforced by association between MAP3K5 and atopy ${ }^{19}$. IKBKE is a known target of the nuclear factor KB (NFKB), a transcription factor involved in chronic inflammation of established role in asthma pathogenesis, including remodeling.

\subsection{Literature-based assessment of individual DCGs for mechanistic role in EA and bronchial remodeling.}

Individual DCGs are discussed below in the following order: gene's function, possible involvement in the disease and interaction with other DCGs from our study (shown in bold). 


\subsubsection{Sodium/potassium-transporting ATPase subunit beta-1 (ATP1B1)}

The sodium-potassium pump is a heterodimer composed of the catalytic subunit alpha and non-catalytic subunit beta. The latter may be expressed in several cell types and conditions involved in asthma pathogenesis:

(1) In the epithelia, the beta-1 subunit may be related to epithelial sheathing as it contributes to formation and stabilization of intercellular junctions. It regulates the number of pumps transported to plasma membrane through assembly of alpha/beta heterodimers, which can act as positive or negative regulator of intracellular adhesion, depending on its proportion to FXYD5, a membrane protein involved in chemokine up-regulation and loosening of cell adhesion through down-regulation of E-cadherin ${ }^{20}$.

(2) In cytomegalovirus (CMV) infection, previously linked to asthma pathogenesis via promotion of Th2 response ${ }^{2122}$, subunit beta 1 was found to co-localize with viral UL136 protein suggesting involvement in cell-to-cell spread of the infection ${ }^{23}$. It is also upregulated in human neutrophils during respiratory syncytial virus (RSV) infection, a trigger of asthma exacerbations.

(3) In lymphocytes, subunit beta 1 is known to be up-regulated in response to phytohemagglutinin, suggesting possible role as marker of their activation status ${ }^{24}$ and AT1B1 was among four genes upregulated in human lymphocytes under Th17-polarizing conditions.

(4) Decreased activity the pump elevates intracellular free calcium concentration, a phenomenon linked to the activation of inflammatory cells and airway smooth muscles (ASM) resulting in increased proliferation, spreading, and eosinophil-attracting eotaxin-1 release in experimental conditions ${ }^{25262728}$.

(5) In the goblet cells, IL-4 produced by Th2-lymphocytes causes up-regulation and translocation of ATP1B1 from basal to apical aspect of the cell, where it colocalizes with H+/K+-ATPase, ATP12A, being required for its function implied in mucous secretion in asthma and cystic fibrosis ${ }^{29}$.

(6) ATP1B1 is modulated by PXK, which is thought to participate in regulation of electrical excitability and synaptic transmission by, in part, epidermal growth factor (EGF) receptor ligand-induced internalization ${ }^{30}$, both processes being postulated to play a role in airway hyperreactivity in asthma.

ATP1B1, CLC, FADS6, FBN3, RECK and SLC19A1 share a common transcription factor Sp1 ${ }^{313233}$ involved in multiple cellular processes ranging from cell proliferation and differentiation to immune response, their specific function being highly dependent on post-translational modification. Sp1 expression and DNA binding activity are increased in CMV infection ${ }^{34}$, a positive-feedback loop given ATP1B1's role in cell-tocell virus transmission. Furthermore, $\mathrm{Sp} 1$ has an established role in asthma pathogenesis as a transcription factor for (1) lipooxygenase $\mathrm{ALOX} 5^{35}$, which promoter region's polymorphism affects asthma control, and (2) vascular endothelial growth factor (VEGF), hypersecreted from ASM in asthma and 
contributing to remodeling. Of note, both ATP1B1 and RECK are implied to take part in airway remodeling in mustard lung ${ }^{36}$, adding to evidence of Sp1-regulated genes in airway pathology.

ATP1B1 was one of the genes included in transcriptomic cluster TAC3 of patients with moderate to high sputum eosinophilia in the U-BIOPRED cohort of Th2-dependent asthma ${ }^{37}$, with our study being the second to indicate the link.

Of note, as ATP1B1 is involved in kidney proximal tubule bicarbonate reclamation, aldosterone-regulated sodium reabsorption and kidney stone formation, common regulation of ATP1B1 in both bronchi and renal tubule may underlie apparent higher incidence of nephrolithiasis and chronic kidney disease in asthma patients ${ }^{3839}$.

\subsubsection{Charcot-Leyden crystal protein (CLC)}

Charcot-Leyden crystal protein or galectin-10 (Gal-10) is an atypical galectin preferentially binding bmannosides. It takes part in sequestration and vesicular transport of eosinophil granule cationic ribonucleases: eosinophil-derived neurotoxin and eosinophil cationic protein ${ }^{40}$ and was found to poses lysolecithin acylhydrolase (lysophospholipase; phospholipase B) activity. Released upon degranulation, it is ubiquitous in sputum of EA patients and considered a marker of eosinophilic inflammation. It is thought to regulate immune responses through the recognition of cell-surface glycans and may possess IgEbinding capability. Furthermore, through lysophospholipase activity, it may hydrolyze 1) phospholipids, producing arachidonic acid for synthesis of eicosanoids of important role in asthma pathogenesis and 2) surfactant phosphatidylcholine, leading to surfactant dysfunction and small airway closure ${ }^{41}$.

Recently, the existence of regulatory CD16-high eosinophils with distinct suppressor function on T-cell proliferation has been suggested, with their function likely mediated by Gal-10 in immune synapses between eosinophils and lymphocytes ${ }^{42}$. Furthermore, Gal-10 was recently found to be expressed in human CD4(+)CD25(+)Foxp3(+) T regulatory cells (Treg), while nearly absent in resting and other activated CD4(+) $T$ cells. In Treg cells this lectin is essential to limit proliferation and suppressive function, similarly to the above CD16-high eosinophils ${ }^{43}$.

CLC shares transcription factor Sp1 with ATP1B1, RECK, FBN3, FADS6 and SLC19A1, which points to a possible involvement in a common biological process.

Consequently, CLC was included in transcriptomic cluster TAC1 of patients with high sputum eosinophilia in the abovementioned U-BIOPRED asthma study ${ }^{37}$ and associated with asthma in an epigenome-wide association study (EWAS) ${ }^{44}$.

Since galectins can frequently act as both positive and negative modulators of the same processes, possibly depending on isoform plasticity, posttranslational modifications, localization or cofactors ${ }^{45}$, further research is needed to assess if galectin-10 can be influenced to act as an anti-inflammatory factor, similar to galactin-9 (Gal-9). This galectin, released by various cell types plays a substantial role in control 
of effector cells and Th1/Th2 balance. It is known to be upregulated upon CMV infection through induction of IFN-b ${ }^{46}$ and released upon calcium-mediated exocytosis ${ }^{47}$. It is able to reduce Th2-associated airway inflammation and airway hyperresponsiveness through binding with $\mathrm{T}$ cell immunoglobulin mucin domain 3 (Tim-3), persistently expressed on functional T-cells during chronic viral infections. By inducing maturation of monocyte-derived dendritic cells it promotes Th1-associated immune response. It also triggers apoptosis of mature Th1 cells by aforementioned Tim-3 receptor, preventing degranulation of mast cells by forming complex with $\lg ^{48}$ and inhibits interaction-dependent migration of inflammatory cells via CD44 pathway ${ }^{49-52}$. These properties elicit galectin-9 and possibly galectin-10 as potential candidates for development of novel protein drugs for the treatment of asthma.

\subsubsection{Pregnancy-specific beta-1-glycoprotein 2 (PSG2)}

PSG2 stimulates transcription of FOXP3 in mononuclear cells and CD4+ T cells, thus providing signal for Treg and Th17 differentiation, a process consistent with CLC/Gal-10 expression on CD4(+)CD25(+)Foxp3(+) Treg cells, with loss of FOXP3 expression causing Th2-differentiation ${ }^{53}$. Human PSG proteins are able to activate latent TGF-b bound to the extracellular matrix and cell membrane, thus enabling its pleiotropic action ${ }^{54}$ involved in suppression of innate immunity, Th17 differentiation, expression of T-cell regulatory phenotype but also up-regulation of periostin, a component of subepithelial fibrosis in asthma ${ }^{55}$.

Co-expression of the two genes involved in limitation of Th2- and induction of Th17-differentiation, CLC and PSG2, in EA patients suggests both a counterweight mechanism to limit Th2-response and a possible role behind heterogeneity of Th2-high asthma, recently proposed to be divided into IL-5-high/IL-17F-high asthma (with mixed granulocytic infiltration) and IL-4/IL-13-high asthma (with eosinophilic infiltration alone) $)^{56}$.

\subsubsection{EPS8 like 1 (EPS8L1)}

EPS8L1 encodes a protein related to the epidermal growth factor receptor kinase substrate 8 or Eps8 involved in actin remodeling. EPS8L1 itself is known to play a role in T-cell receptor binding, membrane ruffling and remodeling of actin cytoskeleton through F-actin organization by stimulating guanine exchange of SOS1, thus taking part in regulation of cell locomotion. In a murine knockout models, EPS8L1 was required for EGF-dependent membrane ruffling ${ }^{57}$ and Eps8 was required for maintaining front-to-back polarity of dendritic cell, both features required for cell migration ${ }^{58}$. Furthermore, Eps8 takes part in Cdc42IRSp53-Eps8 pathway involved in formation of filopodia and cell migration, with EPS8L1 being the only Eps8-related protein associating with IRSp53 and thus possibly involved in the process ${ }^{59}$.

No direct link between EPS8L1 an asthma was made to date.

Cell migration is a regulated by Rho GTPases, of which RhoBTB2 is an example, although no associations between Eps8 or EPS8L1 exist to date. 


\subsubsection{Rho related BTB domain containing 2 (RHOBTB2)}

RHOBTB2 is an atypical member of the Rho family of small GTPases which control cell migration, invasion and cycle and is required for expression of CXC motif ligand 14 (CXCL14). CXCL14 is a chemoattractant that controls dendritic cell activation, leukocyte migration and angiogenesis and an autocrine growth factor for fibroblasts facilitating their migration ${ }^{60}$ and which expression is lost through unknown mechanisms in a wide range of epithelial cancers ${ }^{61}$; e.g., loss of RhoBTB2 expression correlates with downregulation and loss of CXCL14 secretion by head and neck squamous cell carcinoma cell lines, whereas reintroduction of RhoBTB2 restores CXCL14 secretion ${ }^{62}$.

In a genome-wide association study conducted in Australia, CXCL14 was one of the six most-associated loci with the asthma susceptibility ${ }^{63}$. Moreover, effects of exposure to tobacco smoke pollution are thought to be mediated through the CXCL14. The experimental data suggests differential effects of occasional ${ }^{64}$ and chronic ${ }^{65}$ tobacco exposure on CXCL14 expression, as well as differential effects of tobacco smoking on airway eosinophilia (elevated in chronic smokers, but attenuated by occasional exposure in non-smokers).

While CXCL14 receptor is not yet identified, migration of antigen-presenting cells (APCs) towards CXCL13, the ligand of CXCR5, is significantly potentiated in the presence of CXCL14, possibly contributing to mucosal recruitment of inflammatory cells ${ }^{66}$, including APCs and Th17 lymphocytes expressing CXCR5 as well. Regulation by RhoBTB2 suggests its role in disease mediated through CXCL14 and resulting migration of leukocytes, dendritic cells and possibly epithelial-mesenchymal transition of fibroblasts.

Furthermore, RhoBTB2 is a substrate adaptor for Cul3-based ubiquitin ligase complex known to play a role in a Keap1-guided degradation of antioxidative Nrf transcription factor implicated in asthma pathogenesis ${ }^{67}$. As Keap1 is believed to compete with other BTB proteins for culling-3 binding, downregulation of RhoBTB2 may leave E3 ubiquitin ligase open for adaptor Keap1-BTB-mediated ubiquitination and degradation of antioxidative Nrf2, thus suppressing its transcriptional activity and promoting oxidative stress. Recent studies indicate that RhoBTB2 is involved in the Hippo signaling pathway through LKB1 regulation, with loss of RhoBTB2 leading to ubiquitination and loss of LKB1 as well as increased YAP activity of role in asthma pathogenesis. Available GEO dataset indicates correlation between RhoBTB2 expression and asthma exacerbation, with significant difference in expression between pools of peripheral blood mononuclear cells from exacerbated and convalescent asthma patients (GDS3615 ${ }^{68}$ ). Furthermore, RhoBTB2 was one of the genes which expression changed significantly after bronchial thermoplasty ${ }^{69}$.

RhoBTB2's GTPase activity as well as interaction with Cul3 requires Hsp90, a chaperone regulated by $\mathrm{CCT7}^{70}$. Its role in membrane ruffling makes a possible link with aforementioned EPS8L1.

\subsubsection{Ras association (RalGDS/AF-6) and pleckstrin homology domains (RAPH1)}

RAPH1 is a member of Mig10/Rap1-interacting family of adaptor proteins regulating actin dynamics. As a mediator of localized membrane signaling implicated in the regulation of lamellipodial dynamics it 
regulates cell migration, and its internalization negatively regulates cell adhesion, possibly contributing to epithelial sheathing. Phosphorylation of RAPH1 by C-abl oncogene takes part in its coordination of actin remodeling in response to external stimuli ${ }^{61}$. As a target gene of regulatory miR-203, it facilitates keratinocyte migration and wound healing ${ }^{71}$. While no direct role of RAPH1 in airways was reported, miR203 is known to inhibit proliferation in ASM cells through attenuation of c-Abl expression and phosphorylation by ERK1/2, a pathway involved in epithelial-mesenchymal transition in airways, of which RAPH1 is a phosphorylation target. Furthermore, both ERK1/2 and RAPH1 are affected by histone demethylase KDM2A, implicated in lung carcinogenesis ${ }^{72}$. Because of its place at the intersection of KDM2A, miR-203, c-Abl and ERK1/2, RAPH1 upregulation in EA patients suggests its role in ASM proliferation, as well as epithelial sheathing and epithelial-mesenchymal transition.

\subsubsection{Signal recognition particle receptor beta subunit (SRPRB)}

SRPRB is one of two subunits of the signal recognition particle receptor (SRP) required for co-translational targeting of secretory and membrane proteins. With the alpha subunit targeting SRP-ribosome-nascent polypeptide complexes to translocon, the beta subunit is a transmembrane GTPase which anchors the alpha subunit to the endoplasmic reticulum (ER).

Protein-protein interaction studies suggest SRPRB as involved in trafficking of proteins relevant for asthma pathogenesis: (1) beta-2-adrenergic receptor, (2) caspase-4 (a protein of increased expression in alveolar macrophages implied in inflammatory cell death contributing to tissue injury in asthma (https://www.nature.com/articles/s41467-020-14945-2), (3) TNFRSF14 (a receptor for TNF superfamily member TNFSF14 found to promote Th2 lymphocytes and airway remodeling) https://www.nature.com/articles/ncomms13696 and (4) glutathione S-transferase kappa 1 (implied in susceptibility to childhood asthma) ${ }^{73}$.

ILK1, an integrin-linked kinase responding to signals from the extracellular matrix, including injury, and regulating basal stem cell activity and ASM differentiation ${ }^{74}$ links SRPRB to CCT7 through affinity capture protein-protein interaction of unknown biological significance.

\subsubsection{Ankyrin repeat domain 26 pseudogene 1 (ANKRD26P1)}

ANKRD26P1 is a pseudogene of little known function. It interacts with MAGEA-6 ${ }^{75}$, a protein encoding epitopes presented with HLA-DRB1*0401. Presentation of these epitopes recognized by CD4(+) T-cells from patients with melanoma or renal cell carcinoma enhances T-cell response against cells expressing both proteins in HLA-DRB $1 * 0401$ patients ${ }^{76}$. The same haplotype was previously associated with severity of asthma, incidence of rheumatoid arthritis and eosinophilic granulomatosis with polyangiitis, an autoimmune disease resulting in eosinophilic tissue infiltrates and EA phenotype in its clinical presentation ${ }^{77,78}$.

MAGEA-6 is up-regulated upon exposure of cell culture to macrophage migration inhibitory factor (MIF), a pro-inflammatory factor known to play a role in asthma and chronic obstructive pulmonary disease ${ }^{79}$. 
These findings suggest that genetic factors such as human leukocyte antigens may be associated with susceptibility to EA and that it may be mediated through T-cell response against cells expressing

ANKRD26P1 and MAGEA-6, possibly in response to MIF and resulting in T-cell production of IL-4 and IL-13 that drive eosinophilic inflammation.

\subsubsection{Chaperonin containing TCP1 subunit 7 (CCT7)}

CCT7 is a molecular chaperon, member of chaperonin containing TCP1 complex (CCT; TRiC) assisting folding of proteins like actin and tubulin and regulating Hsp90 chaperone.

Its expression increases in fibrotic wound healing and is essential for the accumulation of a-smooth muscle actin (a-SMA) in fibroblasts and cell differentiation to myofibroblasts ${ }^{80}$. CCT7 was recently found to coimmunoprecipitate with thromboxane $A 2$ receptor as well as $\beta 2$-adrenergic receptor from human HEK 293 cells and its depletion resulted in reduced cell surface expression of both receptors ${ }^{81}$; a fact significant given the momentous role of both G-protein coupled receptors in asthma pathogenesis. Two-hybrid screening revealed interaction between CCT7 and ANXA1, which deficiency causes spontaneous airway inflammation and hyperresponsiveness in murine studies ${ }^{82}$.

Notable is the CCT7's central position in the PPI network of multiple DCGs and their interactors of high asthma literature coverage (Fig. 4) and involvement in epithelial-mesenchymal transition, implying regulatory function of the CCT/TRiC complex in asthma pathogenesis, involving e.g. Hsp90-dependent GTPase activity of RhoBTB2.

\subsubsection{Deiodinase iodothyronine type III (DIO3)}

DIO3 product catalyzes the inactivation of thyroid hormone by inner ring deiodination of the prohormone thyroxine (T4) and the bioactive hormone 3,3',5-triiodothyronine (T3) to inactive metabolites, 3,3',5'triiodothyronine (RT3) and 3,3'-diiodothyronine (T2), respectively. DIO3 is thought to prevent fetal tissues from exposure to adult-level concentrations of thyroid hormones.

TGF-b is known to induce DIO3 expression in various cell types, including lung fibroblasts. Of note, deiodinase type III is a selenoprotein while selenium deficiency has been suggested to take part in inflammatory diseases including asthma ${ }^{83}$ through contribution to oxidative stress, a mechanism thought to underlie asthma exacerbations in hyperthyroidism. As oxidative stress is implied to induce DIO3 expression, asthma exacerbations in selenium deficiency are aggravated through impaired DIO3 function and increased tissue exposure to active thyroid hormones. No direct link between DIO3 and asthma has been made to date, however, its upregulation might be a response to oxidative stress, activation of fetal genes due to tissue repair (along with FBN3 and GPI, below) or adult overexpression of genes hypermethylated prenatally, contributing to the hypothesis of prenatal epigenetic changes as predisposing to asthma development ${ }^{52}$. Promotor of the above-mentioned ATP1B1 has sequences binding thyroid hormones (TRE), forming a link to upregulation of both ATP1B1 and DIO3 in our study.

\subsubsection{Epidermal growth factor receptor pathway substrate 15 (EPS15)}


EPS15 is a protein involved in the clathrin-dependent internalization of ligand-inducible tyrosine kinase receptor (RTK) types (including EGFR, TGF-b receptors and integrin b-1) as well as cell adhesion molecules (integrins, E-cadherin), receptors relevant for bronchoconstriction ( $\beta 2$-adrenergic and M3-muscarinic receptors) and antigen-presenting major histocompatibility class II proteins.

EPS15 is also necessary for non-clathrin-dependent endocytosis of EGFR and TGF-b, with knockout models resulting in attenuated TGF- $\beta$-induced Smad2 phosphorylation ${ }^{84}$ of role in fibroblast to myofibroblast transition ${ }^{85}$.

EPS15 forms PARK2-EPS15-EGFR complex with parkin, an E3 ubiquitin ligase influenced by IL-13 and known to enhance airway mitochondrial DNA release contributing to inflammation ${ }^{86}$. Since IL13-stimulated parkin aids mono-ubiquitination of EPS15 thus preventing RTKs internalization and potentializing the effects of TGF-b, it forms a link between the two pro-fibrotic cytokines as well as mtDNA-mediated inflammation.

EPS15L1, a protein of suggested role in the process of receptor endocytosis, coimmunoprecipitates with EPS15 and is one of the genes associated with asthma in an EWAS study ${ }^{44}$ and EPS15 transcript is upregulated in human ASM cells upon their stimulation ${ }^{87}$.

EPS15 and TTC3 (a gene homologous with TTC3P1) are potential binding partners of Eps15 homology domain-containing 1 (EDH1), a protein involved in endocytic receptor recycling ${ }^{88}$.

\subsubsection{Fatty acid desaturase 6 (FADS6)}

FADS6 is an peroxisomal enzyme of oxidoreductase activity taking part in aerobic very long chainpolyunsaturated fatty acids (PUFAs) biosynthesis. By desaturating linoleic acid to g-linoleic acid, it contributes to synthesis of arachidonic acid, precursor of eicosanoids of established role in asthma pathogenesis, in a similar fashion to FADS1 and FADS2 implicated in asthma pathogenesis ${ }^{8990919293}$. FADS6 is regulated by hsa-miR-331-3p, a micro-RNA post-transcriptional regulator associated with lung function in asthma, with our study supplying evidence for the mechanism of such association being mediated through FADS6 ${ }^{94}$. FADS6 promoter binds factors reported to influence asthma risk: EZH2, as well as abovementioned Sp1, a transcription factor for ATP1B1, FBN3, RECK and SCL19A1.

\subsubsection{Fibrillin 3 (FBN3)}

Fibrillins are components of extracellular calcium-binding microfibrils, which occur either in association with elastin or in elastin-free bundles and act as structural support important for extracellular matrix integrity. Like PSG2, fibrillins may be involved in regulation of TGF-b activity through association with latent TGF-b binding proteins. Physiological FBN3 expression was described only in fetal developing bronch ${ }^{9596}$, but its mutations have been found in lung cancer ${ }^{97}$. It shares a common transcription factor Sp1 with ATP1B1, FADS6, RECK, SLC19A1 ${ }^{33}$. Up-regulation of the FBN3 gene in the current gene set might both reinforce the hypothesis of fetal program execution during bronchial remodeling (together with GPI 
and DIO3), regulation of signaling through latent TGF-b and add to a weak association between lung cancer and asthma ${ }^{98}$.

\subsubsection{Glucose-6-phosphate isomerase (GPI)}

GPI expresses differential function depending on location, being (1) an intracellular glycolytic enzyme that interconverts glucose-6-phosphate and fructose-6-phosphate (thus taking part in glycolysis, gluconeogenesis and pentose phosphate pathway), (2) an extracellular neurotrophic factor neuroleukin that promotes survival of skeletal motor neurons and sensory neurons in fetal development, (3) a lymphokine that induces immunoglobulin secretion and (4) an autocrine motility factor (AMF) acting as an angiogenic factor.

GPI has a proven pathogenetic role in rheumatoid arthritis, acting as an autocrine synovial fibroblast proinflammatory cytokine resulting in proliferation, apoptosis inhibition and secretion of tumor-necrosis factor (TNF)-a and IL-1 $\beta^{99}$. Immunization of murine CD4(+) T-cells against GPI causes experimental model polyarthritis with production of proinflammatory TNF-a, IL-17 and IL- 6 and anti-GPI autoantibodies are detectable in some human rheumatoid arthritis patients. GPI was found to be a direct regulator VEGFmediated angiogenesis in rheumatoid arthritis, with both proteins being up-regulated by HIF-1a, a transcription factor involved in airway remodeling. Though rheumatoid arthritis is classically considered as Th1-dependent disease, it seems to share genetic risk factors and elements of pathogenesis with asthma ${ }^{100}$. Further studies are needed to assess if anti-GPI is present in sputum of asthma patients similarly to anti-eosinophil peroxidase and anti-IgE autoantibodies and if VEGF-mediated airway remodeling is regulated by GPI in similar fashion to that seen in rheumatoid arthritis.

As an enzyme taking part in glycolysis, it may affect glucose metabolism in the airway epithelia, where hyperglycemia and impaired glucose transport induce cell proliferation ${ }^{101}$. Association with asthma in an EWAS ${ }^{44}$ adds evidence of its pathogenetic role. Its role in fetal development along with DIO3 and FBN3 may be indicative of fetal genetic program execution in asthmatic airways.

\subsubsection{Mitochondrial ribosomal protein L14 (MRPL14)}

MRPL14 is a nuclear gene that encodes part of two intersubunit bridges in the assembled mitochondrial ribosome required for mitochondrial translation. Related to asthma in a genome-wide association study ${ }^{102}$ and controlled by MYC transcription factor similarly to DGLUCY, it may be involved in asthma-specific mitochondrial biogenesis and accumulation in ASM.

\subsubsection{Olfactory receptor family 52 subfamily I member 1 (OR52/1)}

OR5211 is an olfactory receptor functioning by CaBP/Cam-dependent inhibition of calcium channel, a function which may be influenced by CABP5 due to functional replaceability with calmodulin. While no link between OR52I1 and asthma was found to date, other olfactory receptors like OR1D2 and OR2AG1 are known to be expressed in ASM cells and their activation by amyl butyrate was shown to inhibit histamine- 
induced ASM contraction. OR52I1 and CABP5 may thus be involved in pathology of airway hyperreactivity in asthma of undetermined significance.

\subsubsection{Protein phosphatase 2 regulatory subunit B beta(PPP2R3B)}

PPP2R3B might modulate its substrate selectivity and catalytic activity and direct the localization of the catalytic enzyme to a particular subcellular compartment. Also known as PR48, it regulates cell cycle progression likely by controlling initiation of DNA replication ${ }^{103}$. It's downregulation in EA may indicate increased airway or inflammatory cell proliferation.

\subsubsection{Reversion inducing cysteine rich protein with kazal motifs (RECK)}

RECK is a membrane-anchored negative regulator of matrix metalloproteinase-9 (MMP)-9 able to suppress its secretion and enzymatic activity. MMP-9, a gelatinase, is known to be secreted by epithelial cells, neutrophils and eosinophils in response to allergen challenge or TNF-a and was previously linked to both eosinophilic infiltration into the bronchial wall and remodeling as a major MMP involved in asthma ${ }^{104}$. Its activity is increased in sputum of asthmatic patients and correlates with loss of FEV1 in response to allergens ${ }^{105}$. Furthermore, RECK down-regulation by oncogenic signals may facilitate tumor invasion and metastasis through regulation of MMP-2 and MT1-MMP, further linking asthma and carcinogenesis. It shares a common transcription factor Sp1 with ATP1B1, FADS6, FBN3 and SLC19A132.

\subsubsection{Scavenger receptor cysteine rich family member with 4 domains (SSCRB4D)}

SSCRB4D belongs to the scavenger receptor cysteine-rich (SRCR) superfamily of highly conserved proteins involved in the development of the immune system and regulation of immune responses. SSCRB4D may be associated with asthma by being one of the target genes of $\mathrm{BACH} 1$, involved in the response to oxidative stress and previously associated with asthma in an EWAS study ${ }^{44}$.

\subsubsection{Stomatin like 3 (STOML3)}

STOML3 modulates mechanotransduction channels and acid-sensing ion channels (ASIC) proteins and potentiates PIEZO1 and PIEZO2 function by increasing their sensitivity to mechanical stimulations. Studies in animal models suggest that mechanotransduction may play a role in hyperresponsiveness of the airways in asthma, while PIEZO1 deficiency decreases cell adhesion and increases migration of lung epithelial cells ${ }^{106}$, a feature of asthmatic bronchial remodeling ${ }^{107}$.

\subsubsection{Striatin-4 (STRN4)}

STRN4 belongs to a family of proteins binding calmodulin in a calcium-dependent matter, which may function as scaffolding or signaling protein. It is known to co-localize with protein phosphatase 2A (PP2A) acting as a regulatory subunit of the STRIPAK kinase-phosphatase complex involved in multiple cellular processes. Animal studies suggest that STRIPAK might be involved in cell cycle control, cell adhesion, migration, epithelial integrity and epithelial-to-mesenchymal transition. 
STRN4, by inhibition of MAP4K4 kinase, is considered the key regulator inhibiting the Hippo pathway involved in asthma pathogenesis ${ }^{108}$. In T-cells, deficiency of MAP4K4 results in Th17 differentiation with IL-6 and IL-17 expression ${ }^{109}$. In a study of asthmatic patients, miRNAs expressed in the airways frequently targeted MAP kinases including MAP4K $4{ }^{110}$, suggesting their involvement in the disease.

STRN4 itself was also proposed as a part of mechanism to control dendritic spine morphology, adding to possible neuronal involvement in airway disease.

STRN4 is one of the genes associated with asthma in an EWAS ${ }^{44}$.

Through STRN4, STRIPAK interacts with Mob3, NDPK, dynamin and abovementioned EPS15 to take part in regulation of clathrin-dependent endocytosis (e.g. of EGF, TGF-b or $b_{2}$-adrenergic receptors) ${ }^{111}$.

\subsubsection{Tetratricopeptide repeat domain 3 pseudogene 1 (TTC3P1)}

TTC3P1 is a pseudogene resembling TTC3, a E3 ubiquitin-protein ligase that mediates ubiquitination of phosphorylated Akt (AKT1, AKT2 and AKT3) as part of negative feedback required to control Akt levels after pathway activation. TTC3 contributes to TGF-b1-induced epithelial-mesenchymal transition any myofibroblast differentiation, forming a direct link with bronchial remodeling ${ }^{112}$. TTC3 may also play a role in neuronal differentiation inhibition via its interaction with CIT, associated with asthma in GWASdb database $^{102}$, a fact of potential significance for the neuronal involvement in the disease ${ }^{113}$. As an apparently transcribed pseudogene, TTC3P1 may regulate TTC3 function. Membership in a E3 ligase complex associated with CUL3 links TTC3 to RhoBTB2 while involvement in Akt pathway makes an association with ASB3.

\subsubsection{Calcium binding protein 5 (CABP5)}

CABP5 product inhibits calcium-dependent inactivation of L-type calcium channel, thus increasing cell excitability. While primarily involved in the transmission of light sensation in the retina, it was reported in Tcells including Th1, Th17, mucosa-associated invariant T (MAIT) cells and B-cells, being differentially expressed in allergic asthma patients ${ }^{114}$ ). Together with the involvement in stimulating neurite outgrowth and vesicle exo- as well as endocytosis in PC12 cells, these facts suggest that CABP5 plays a role in immune reactions, neuronal growth (a feature of airway remodeling) and vesicle handling. Able to functionally replace calmodulin, it may potentially interact with striatin in clathrin-dependent membrane receptor endocytosis, thus relating CABP5 to STRN4 and EPS15 ${ }^{115}$.

\subsubsection{Ribosomal protein S13 (RPS13)}

RPS13 is a component of the 40S ribosomal subunit essential for eukaryotic protein synthesis and regulated through redundant mechanisms, hence described as a reference housekeeping gene. However, it is known to take part in $\mathrm{G} 1$ to $\mathrm{S}$ cell phase transition and was featured in cluster 1 of asthma-linked modules obtained from the combination of differential gene expression and GWAS study of the U-BIOPRED project $^{116}$. Furthermore, it forms TNF-a/NF-Kappa B signaling complex of established role in asthma ${ }^{67}$. 
These data provide arguments for viewing RPS13 as an active player in asthma pathogenesis and reevaluate it as a reference housekeeping gene of seemingly stable expression across biological conditions. Affinity capture studies indicate interactions of RPS13, CCT7 and EPS15 with VCAM1, ITGA4, FN1 proteins involved in cell-cell and cell-extracellular matrix adhesion, with VCAM and FN1 both binding to ITGA4, as subunit of integrin a4b1. While the nature of the interaction between proteins involved in extracellular matrix and endocytosis, regulation of chaperones and ribosome structure is unknown.

\subsubsection{Ankyrin Repeat And SOCS Box Containing 3 (ASB3)}

ASB3 is part of ASB gene family involved in Erk1/2 and PI3K/Akt signal transduction pathways by regulation of MAP kinase and Akt phosphorylation, both implicated in smooth muscle proliferation in asthma ${ }^{117}$.

It may regulate lymphocyte differentiation through TNF-a receptor (TNFR) 2 ubiquitination by recruitment of E3 ubiquitin ligase adaptors: elongins-B/ $\mathrm{C}^{118}$. While TNFR2 initiates immune modulation and tissue regeneration, signaling through TNFR1 triggers pro-inflammatory pathways ${ }^{119}$. Loss of TNFR2 signaling can impair expansion and stability of Tregs and decrease their sensitivity to IL-2. Moreover, through reciprocal PI3K/Akt pathway activation and phosphorylation of STAT5, ASB3 impairs Th17 differentiation and may impair IL-12 signaling through JAK2/STAT4 to favor Th2 rather than Th1 differentiation ${ }^{120}$, resulting in predominantly eosinophilic, rather than neutrophilic inflammation.

Recent GWAS study has associated three SNPs in a region of chromosome 2 near ASB3 and SOCS with degree of bronchodilation following inhalations of albuterol in asthma patients ${ }^{121}$, with our study indicating ASB3 as an agent in the disease pathogenesis.

\subsubsection{Solute carrier family 19 member 1 (SLC19A1)}

SLC19A1, also referred to as reduced folate carrier protein, is a bidirectional membrane anion transporter enabling both folate and anti-folate medications, e.g. methotrexate (MTX) influx into the cell. Folate is required for synthesis of purines and thymine, homocysteine-methionine metabolism, both homocysteinedependent and independent production of nitric oxide and reactive oxygen species (ROS) as well as DNA methylation, exerting both anti-inflammatory and pro-inflammatory properties, possibly depending on chronicity of an inflammatory disease ${ }^{122}$.

Folate deficiency was previously linked to asthma severity ${ }^{123}$ as well as risk of developing the disease in children of folate-deficient mothers ${ }^{124}$. It affects fibroblast expression of genes related to cytoskeleton remodeling, extracellular matrix and signaling through Wnt pathway (DKK1, WISP1 and WNT5A) ${ }^{125}$ and may affect collagen metabolism in concomitant ascorbic acid deficiency. Folate deficiency increases the CD4/CD 8 ratio and murine models indicate its role in maintaining CD4(+)Foxp3(+) regulatory T-cells, decreased in human asthma patients ${ }^{126}$. 
Furthermore, as a recently discovered major transporter of immunoreactive cyclic dinucleotides (CDN) of autologous or microbial origin ${ }^{127}$, SLC19A1 may take part in dysregulation of the cGAS-STING pathway which overactivation can drive inflammatory lung diseases, including asthma ${ }^{128}$.

A genetic risk factor of atopy, an SNP rs12483377-A is mapped to SLC19A1 and COL18A1, both functionally implied in the process ${ }^{19}$.

Up-regulation of SLC19A1 may be driven by transcription factors linked to asthma (CEBPB, USF1, SP1), Th2-differentiation (CEBPB) ${ }^{122}$ and asthma-specific mitochondrial biogenesis (NRF-1). Furthermore, it is up-regulated by vitamin $D^{129}$, which deficiency was previously linked to asthma control. Differential coexpression in EA may indicate both activity of the above transcription factors, cell proliferation status or impaired reaction to folate deficiency, a condition under which SLC19A1 is considered cytotoxic, since it may aggravate folate deprivation by expulsion of folate monoglutamates ${ }^{130}$. These facts indicate that SLC19A1 may have pathogenetic role in asthma, being affected by both transcription factors involved in asthma and nutritional status linked to asthma risk and severity.

We hypothesize that ill-regulated overexpression of SLC19A1 by activity of transcription factors to asthma pathogenesis in a bystander effect may sensitize cells to pro-inflammatory effects of self- and microbial DNA or aggravate cell folate deprivation, activating cGAS-STING pathway or creating a vicious cycle of abnormal DNA methylation and exhibition of folate's pro-inflammatory properties.

Co-expression of SLC19A1 in EA patients may have therapeutic implications, since MTX is consideration as steroid-sparing medication for severe asthma patients and its transport may affect treatment outcomes.

\subsubsection{MAEA (macrophage erythroblast attacher, E3 ubiquitin ligase).}

MAEA is an ubiquitin ligase and part of CTLH complex of significance in TNF-a-mediated apoptosis, as well as erythropoiesis and macrophage maturation. An EWAS found association between trans-CpG site in MAEA and IL1RL1a, an isoform of IL1RL1 associated with multiple immune reactions in the lung, including Th2-response ${ }^{131}$. MAEA methylation positively correlated to birth weight in an observational study ${ }^{132}$, suggesting possible mechanistic association between obesity, MAEA and IL1RL1a activity in asthma. As an apoptosis-related gene it is up-regulated upon exposure to cigarette smoke extract, possibly due to circulating TNF-a, placental growth factor or loss of VEGF signaling, as well as RSV exposure, along with MMP-9133.

\subsubsection{DGLUCY (D-glutamate cyclase; C14orf159).}

C14orf159 is a nuclear gene encoding mitochondrial protein recently identified as D-glutamate cyclase (DGLUCY) converting D-glutamate to 5-oxy-proline (pyroglutamic acid).

DGLUCY can be linked to asthma through (1) impact on E-cadherin expression (involved in to epithelial integrity in asthma), possibly through inhibition of ERK and P90RSK phosphorylation ${ }^{134}$, (2) its suppression by miRNA-199b (overexpressed during bacterial but not viral infections) ${ }^{135}$, (3) possibly 
related differential expression in neutrophilia ${ }^{136},(4)$ strong differential expression implied in seasonal remodeling of the immune system (reinforcing its role in immune system function and possibly regulation $)^{137}$.

Expression of DGLUCY is influenced by signaling through oestrogen receptor alpha ${ }^{137}$, possibly adding to mechanisms of different asthma phenotypes between sexes. Similarly to abovementioned MRPL14, it is a downstream target of MYC, a transcription factor promoting mitochondrial biogenesis and oxidative metabolism in preparation for mitosis and obligatory for cell cycle entry and progression, with NRF-2 and MYC-interacting YY1 being the other transcription factor involved. Invertebrate studies of potential human application, given highly conservative nature of DGLUCY, identify MYC as regulated by TOR, FOXO and $\mathrm{PI} 3 \mathrm{~K} /$ Akt pathway in response to nutrient deprivation, linking nutrient availability with macromolecular synthesis enabled by mitochondrial biogenesis ${ }^{138}$.

\subsubsection{RADX (RPA1 related single stranded DNA binding protein, X-linked; CXorf57)}

RADX is one of the genes upregulated upon culture of pericytes under conditions differentiating them into mesenchymal stromal cells ${ }^{139}$. It is recognized, that migration of subepithelial microvascular pericytes contribute to airway remodeling; if involved in asthma, pericytes can form a source of mesenchymal cells for myofibroblast differentiation as in the murine model ${ }^{140}$ and RADX may indicate or mediate such transition.

\subsubsection{Asthma ignorome:}

We couldn't find relevant associations with asthma, inflammation, airway remodeling or other DCGs for GOLGA2P3Y, RP11-321E2.2 and RP3-473B4.3. They will become part of asthma ignorome ${ }^{141}$ of currently unknown role until proven otherwise by future studies.

\subsection{Regulatory networks of differentially co-expressed genes and inferred pathways.}

Regulatory networks of DCGs are presented in Figures 5-6. Associated transcription factors were plotted against betweenness centrality of combined regulatory network to identify highly connected nodes with low literature representation and thus presenting research opportunities (Fig. 7). An enrichment analysis of the transcription factors revealed multiple signaling pathways listed in Tab. 11. Exceptional enrichment of SMAD2/3 nuclear signaling regulation corresponds to profibrotic effects of TGF- $\beta / S$ mad $2 / 3$ pathway involved in fibroblast to myofibroblast transition ${ }^{85}$. Activator protein-1 pathway is necessary for transcription of Th2-profile cytokine IL-4 and indicated as therapeutic target in asthma ${ }^{142} \mathrm{C}$. The E2F/Rb and Wnt/b-catenin pathways are both implied in airway smooth muscle hypertrophy ${ }^{143,144}$. This concordance with current literature validates our results and suggests other less studied pathways as important for future studies.

\section{Summary.}


Systems biology approach allowed us to place 29 of the 32 differentially co-expressed genes in a pathogenetic network with molecular entities previously described as involved in asthma pathogenesis, thus indicating novel candidates for asthma research and highly-connected network disruptors of potential therapeutic applications.

Genes differentially co-expressed in our study bear significance in airway viral infection (ATP1B1, EPS15), arachidonic acid metabolism (CLC, FADS6), cell migration (EPS8L1, STOML3, RHOBTB2), surface receptors endocytosis (STRN4, EPS15, ATP1B1) or decreased expression (CCT7), oxidative stress (DIO3, RHOBTB2), decreased adhesion (ATP1B1, RAPH1, STOML3), epithelial-mesenchymal transition (ASB3, RADX, CCT7, MRPL14, PPP2R3B, RPS13, SLC19A1), myofibroblast differentiation (CCT7), smooth muscle proliferation (ASB3, ATP1B1), airway hyperreactivity (RECK, STOML3, ATP1B1, OR5211), extracellular matrix remodeling (FBN3, RECK), angiogenesis (GPI, RHOBTB2) and neuronal pathogenesis of asthma (OR5211, STRN4, TTC3P1, GPI, CABP5) and were associated with asthma in genome-wide (MRPL14, ASB3, RPS13) and epigenome-wide (CLC, EPS15, GPI, SSCRB4, STRN4) association studies.

Study of their regulatory networks allowed us to infer associated pathways involved in asthma, both concordant with current literature (TGF- $\beta / \mathrm{Smad} 2 / 3$ ) and novel to human studies.

Future research should verify the tentative role of DCGs and associated pathways in EA pathogenesis and feasibility of their use as biomarkers of active remodeling and therapeutic targets.

\section{Declarations}

\section{Data availability.}

The datasets generated and analyzed during the current study are available from the corresponding author upon request.

\section{Author contribution statements.}

Concept and design: Stanislawa Bazan-Socha, Jan G. Bazan, Pawel Kozlik

- Acquisition of funding: Stanislawa Bazan-Socha

- Application for bioethics committee approval: Stanislawa Bazan-Socha

- Patient recruitment: Stanislawa Bazan-Socha, Joanna Zuk, Jerzy Soja

- Acquisition of clinical and spirometry data: Stanislawa Bazan-Socha, Joanna Zuk, Jerzy Soja

- Acquisition and analysis of imaging data: Jacek Zarychta

- Acquisition of tissue samples: Jerzy Soja

- Acquisition of genomic data from tissue samples: Aleksander Myszka, Sylwia Buregwa-Czuma, Izabela Zawlik

- Statistical analysis of clinical and spirometry data: Stanislawa Bazan-Socha, Joanna Zuk, Jerzy Soja, Pawel Kozlik 
- Retrieval and co-expression analysis of genomic data: Aleksander Myszka, Sylwia Buregwa-Czuma, Jan G. Bazan, Izabela Zawlik

- Topological analysis, literature mining and ontology enrichment analysis of genomic data: Pawel Kozlik, Andzelika Siwiec

- Drafting the article: Pawel Kozlik

- Preparation of figures and tables: Pawel Kozlik, Andzelika Siwiec

- Critical revision of the article for important intellectual content and final approval of the version to be submitted: Pawel Kozlik, Sylwia Buregwa-Czuma, Izabela Zawlik, Aleksander Myszka, Joanna Zuk, Andzelika Siwiec, Jacek Zarychta, Krzysztof Okon, Lech Zareba, Jerzy Soja, Michał Kępski, Jan G. Bazan, Stanislawa Bazan-Socha

\section{Competing interests.}

The authors (Pawel Kozlik, Sylwia Buregwa-Czuma, Izabela Zawlik, Aleksander Myszka, Joanna Zuk, Andzelika Siwiec, Jacek Zarychta, Krzysztof Okon, Lech Zareba, Jerzy Soja, Michał Kępski, Jan G. Bazan and Stanislawa Bazan-Socha) declare no competing interests.

\section{References}

1. Hough, K. P. et al. B. T. Airway Remodeling in Asthma.Front. Med.7, (2020).

2. Zastrzezynska, W. et al. Musiał J., S. J. Omalizumab may decrease the thickness of the reticular basement membrane and fibronectin deposit in the bronchial mucosa of severe allergic asthmatics. $J$. Asthma. 57:5, 468-477 (2020).

3. Bazan-Socha, S., Zuk, J., Plutecka, H., Marcinkiewicz, C. \& Zareba, L. J. M. Collagen receptors a(1)B(1) and $a(2) \beta(1)$ integrins are involved in transmigration of peripheral blood eosinophils, but not mononuclear cells through human microvascular endothelial cells monolayer.J Physiol Pharmaco/373-379(2012).

4. Kozlik, P. et al. S. The relationship of airway structural changes to blood and bronchoalveolar lavage biomarkers, and lung function abnormalities in asthma. Clin. Exp. allergy J. Br. Soc. Allergy Clin. Immunol. 50 (1), 15-28 (2020).

5. PG, G. Inflammatory phenotypes in adult asthma: clinical applications. Clin Respir J. 198-206 https://doi.org/10.1111/j.1752-699X.2009.00162.x (2009).

6. Sokolowski, J. W., Burgher, L. W., Jones, F. L. \& Patterson, J. R. S. P. Position Paper on Guidelines for Fiberoptic Bronchoscopy in Adults. Am Rev Respir Dis. 136, 1066-1066 (1987).

7. Al., L. R. et. Microarray Image and Data Analysis (CRC Press, Boca Raton, 2014). doi:10.1201/9781315215785

8. Matas, J., Chum, O. \& Urban, M. T. P. Robust wide baseline stereo from maximally stable extremal regions. Proc. Br. Mach. Vis. Conf. 384-396(2002). 
9. Yang, Y. H. et al. Normalization for cDNA microarray data: a robust composite method addressing single and multiple slide systematic variation. 30,1-10(2002).

10. Ritchie, M. E. et al. limma powers differential expression analyses for RNA-sequencing and microarray studies. 43, (2015).

11. Farahbod, M. \& Pavlidis, P. Differential coexpression in human tissues and the confounding effect of mean expression levels. Bioinformatics. 35, 55-61 (2019).

12. Watson, M. CoXpress: differential co-expression in gene expression data. 12,1-12(2006).

13. Chen, E. Y. et al. Enrichr: interactive and collaborative HTML5 gene list enrichment analysis tool.BMC Bioinformatics14, (2013).

14. Azevedo, H. \& Moreira-filho, C. A. Topological robustness analysis of protein interaction networks reveals key targets for overcoming chemotherapy resistance in glioma. Nat. Publ. Gr. 1-13 https://doi.org/10.1038/srep16830 (2015).

15. Du, Y. et al. Nucleosome eviction along with $\mathrm{H} 3 \mathrm{~K} 9 \mathrm{ac}$ deposition enhances Sox2 binding during human neuroectodermal commitment. Cell Death Differ. 24, 1121-1131 (2017).

16. Peixoto, P. et al. EMT is associated with an epigenetic signature of ECM remodeling genes. Cell Death Dis. 10, 205 (2019).

17. ljaz, T. et al. Systems biology approaches to understanding Epithelial Mesenchymal Transition (EMT) in mucosal remodeling and signaling in asthma. World Allergy Organ. J. 7, 13 (2014).

18. Shang, Y. et al. Transcriptional Corepressors HIPK1 and HIPK2 Control Angiogenesis Via TGF- $\beta-$ TAK1-Dependent Mechanism. PLOS Biol. 11, e1001527 (2013).

19. Castro-giner, F. et al. A pooling-based genome-wide analysis identifies new potential candidate genes for atopy in the European Community Respiratory Health Survey (ECRHS).BMC Med. Genet.10, (2009).

20. Tokhtaeva, E. et al. The 0-glycosylated ectodomain of FXYD5 impairs adhesion by disrupting cell-cell trans-dimerization of Na,K-ATPase beta1 subunits. J. Cell Sci. 129, 2394-2406 (2016).

21. Bratke, K., Krieghoff, L., Kuepper, M., Luttmann, W. \& Virchow, J. C. CD 8 + T cell activation and differentiation in allergic asthma and the impact of cytomegalovirus serological status. Clin. Exp. Immunol. 149, 311-316 (2007).

22. Kowalski, M. L. et al. Cytomegalovirus DNA is highly prevalent in the blood of patients with asthma and is associated with age and asthma traits. Allergy. 38, 42-49 (2017).

23. Cui, X. et al. Interaction between human cytomegalovirus UL136 protein and ATP1B1 protein. Brazilian J. Med. Biol. Res. 44, 1251-1255 (2011).

24. Vereninov, A. A. et al. Differential transcription of ion transporters, NHE1, ATP1B1, NKCC1 in human peripheral blood lymphocytes activated to proliferation. Cell. Physiol. Biochem. 11, 19-26 (2001).

25. Chhabra, S. K., Khanduja, A. \& Jain, D. Increased intracellular calcium and decreased activities of leucocyte $\mathrm{Na+}, \mathrm{K}+-$ ATPase and Ca2+-ATPase in asthma. Clin. Sci. (Lond). 97, 595-601 (1999).

26. Chhabra, K., Khanduja, A. \& Jain, D. S \& \& Decreased sodium-potassium and calcium adenosine triphosphatase activity in asthma: modulation by inhaled and oral corticosteroids. he Indian J. chest Dis. allied Sci.15-26(1999). 
27. Sweeney, D. et al. No evidence for altered intracellular calcium-handling in airway smooth muscle cells from human subjects with asthma. BMC Pulm. Med. 15, 12 (2015).

28. Mahn, K. et al. Diminished sarco/endoplasmic reticulum Ca2 + ATPase (SERCA) expression contributes to airway remodelling in bronchial asthma. Proc. Natl. Acad. Sci. U. S. A. 106, 1077580(2009).

29. Scudieri, P. et al. Increased expression of ATP12A proton pump in cystic fibrosis airways.JCI Insight3, (2018).

30. Takeuchi, H., Takeuchi, T., Gao, J., Cantley, L. C. \& Hirata, M. Characterization of PXK as a Protein Involved in Epidermal Growth Factor Receptor Trafficking áo". 30,1689-1702(2010).

31. Li, Z. \& Langhans, S. A. Transcriptional regulators of Na,K-ATPase subunits. Front. cell Dev. Biol. 3,66 (2015).

32. Han, H. et al. TRRUST: a reference database of human transcriptional regulatory interactions. Sci. Rep. 5, 11432 (2015).

33. Davis, M. R. et al. Transcriptional profiling of the human fibrillin / LTBP gene family, key regulators of mesenchymal cell functions. Mol. Genet. Metab. 112, 73-83 (2014).

34. Yurochko, A. D., Mayo, M. W., Poma, E. E. \& Baldwin, A. S. Induction of the Transcription Factor Sp1 during Human Cytomegalovirus Infection Mediates Upregulation of the p65 and p105 / p50 NF- â囚 $\neg$. $B$ Promoters. 71, 4638-4648 (1997).

35. Mougey, E. et al. ALOX5 Polymorphism Associates with Increased Leukotriene Production and Reduced Lung Function and Asthma Control in Children with Poorly Controlled Asthma. Clin. Exp. Allergy. 43, 512-520 (2014).

36. Najafi, A., Masoudi-nejad, A., Ghanei, M., Nourani, M. \& Moeini, A. Pathway Reconstruction of Airway Remodeling in Chronic Lung Diseases: A Systems Biology Approach. 9,1-10(2014).

37. Kuo, C. S. et al. T-helper cell type 2 (Th2) and non-Th2 molecular phenotypes of asthma using sputum transcriptomics in U-BIOPRED. i, $1-14$

38. Huang, H. et al. Bronchial asthma is associated with increased risk of chronic kidney disease. 14,18(2014).

39. Kartha, G. K., Li, I., Comhair, S., Erzurum, S. C. \& Monga, M. Co-Occurrence of Asthma and Nephrolithiasis in Children.1-8(2017). doi:10.1371/journal.pone.0168813

40. Stone, K. D., Prussin, C., Metcalfe, D. D. \& IgE Mast Cells, Basophils, and Eosinophils. 125, 1-16 (2011).

41. Ackerman, S. J., Kwatia, M. A. \& Doyle, C. B. E. G. Hydrolysis of surfactant phospholipids catalyzed by phospholipase A2 and eosinophil lysophospholipases causes surfactant dysfunction: a mechanism for small airway closure in asthma. Chest. 123, 355 (2003).

42. Lingblom, C., Andersson, J., Andersson, K. \& Wennerås, C. Regulatory Eosinophils Suppress T Cells Partly through Galectin-10. J. Immunol. 198, 4672-4681 (2017).

43. Kubach, J. et al. Human CD $4+C D 25$ + regulatory T cells: proteome analysis identifies galectin-10 as a novel marker essential for their anergy and suppressive function. Blood. 110, 1550-1558 (2007). 
44. Hoang, T. T. et al. Epigenome-Wide Association Study of DNA Methylation and Adult Asthma in the Agricultural Lung Health Study. (2020).

45. Brinchmann, M. F., Patel, D. M. \& Iversen, M. H. The Role of Galectins as Modulators of Metabolism and Inflammation. Mediators Inflamm. 2018, ID 9186940 (2018).

46. Merani, S., Chen, W. \& Elahi, S. The bitter side of sweet: the role of Galectin-9 in immunopathogenesis of viral infections. Rev. Med. Virol. 25, 175-186 (2015).

47. Gonçalves Silva, I. et al. The Tim-3-galectin-9 Secretory Pathway is Involved in the Immune Escape of Human Acute Myeloid Leukemia Cells. EBioMedicine. 22, 44-57 (2017).

48. Biology, D., Centre, R. G. \& Review Galectin-9: From cell biology to complex disease dynamics. J. Biosci. 41, 507-534 (2016).

49. Dai, S. Y. et al. Galectin-9 induces maturation of human monocyte-derived dendritic cells. J. Immunol. 175, 2974-2981 (2005).

50. Oomizu, S. et al. Cell Surface Galectin-9 Expressing Th Cells Regulate Th17 and Foxp3 + Treg Development by Galectin-9 Secretion.PLoS One7, (2012).

51. Lhuillier, C. et al. Impact of exogenous galectin-9 on human T cells contribution of the T cell receptor complex to antigen-independent activation but not to apoptosis induction. J. Biol. Chem. 290, 1679716811 (2015).

52. Gunawardhana, L. P., Baines, K. J., Mattes, J., Murphy, V. E. \& Simpson, J. L. G. P. Differential DNA methylation profiles of infants exposed to maternal asthma during pregnancy. Pediatr Pulmonol. 49, 852-862 (2014).

53. Hansmann, L. et al. Dominant Th2 differentiation of human regulatory T cells upon loss of FOXP3 expression. J. Immunol. 188, 1275-1282 (2012).

54. Martínez, F. F., Knubel, C. P., Sánchez, M. C., Cervi, L. \& Motrán, C. C. Pregnancy-specific glycoprotein 1a activates dendritic cells to provide signals for Th17-, Th2-, and Treg-cell polarization. Eur. J. Immunol. 42, 1573-1584 (2012).

55. Peters, M. C., Mekonnen, Z. K., Yuan, S., Bhakta, P. G. \& Woodruff, J. V. N. R. \& F. Measures of gene expression in sputum cells can identify TH 2- high and TH 2-low subtypes of asthma.J Allergy Clin Immunol.133(2),388-394

56. Sven, S. et al. Th2-high asthma: a heterogeneous asthma population ? Clin. Transl. Allergy. 5, 01 (2015).

57. Cheng, C. Y., Lie, P. P. Y., Wong, E. W. P. \& Mruk, D. D. Focal adhesion kinase and actin regulatory/binding proteins that modulate F-actin organization at the tissue barrier: Lesson from the testis. Tissue barriers. 1, e24252 (2013).

58. Frittoli, E. et al. The signaling adaptor Eps8 is an essential actin capping protein for dendritic cell migration. Immunity. 35, 388-399 (2011).

59. Disanza, A. et al. Regulation of cell shape by Cdc42 is mediated by the synergic actin-bundling activity of the Eps8-IRSp53 complex. Nat. Cell Biol. 8, 1337-1347 (2006). 
60. Augsten, M. et al. CXCL14 is an autocrine growth factor for fibroblasts and acts as a multi-modal stimulator of prostate tumor growth. Proc. Natl. Acad. Sci. 106, 3414 LP - 3419(2009).

61. Leary, N. A. O. et al. Reference sequence (RefSeq) database at NCBI: current status, taxonomic expansion, and functional annotation. 44,733-745(2016).

62. McKinnon, C. M., Lygoe, K., Skelton, L., Mitter, R. \& Mellor, H. The atypical Rho GTPase RhoBTB2 is required for expression of the chemokine CXCL14 in normal and cancerous epithelial cells. Oncogene. 27, 6856-6865 (2008).

63. Ferreira, M. A. R. et al. Association between ORMDL3, IL1RL1 and a deletion on chromosome 17q21 with asthma risk in Australia. Eur. J. Hum. Genet. 19, 458-464 (2011).

64. Ishikawa, S., Matsumura, K., Kitamura, N., Takanami, Y. \& Ito, S. Multi-omics analysis: Repeated exposure of a 3D bronchial tissue culture to whole-cigarette smoke. Toxicol. Vitr. https://doi.org/10.1016/j.tiv.2018.10.001 (2018). \#pagerange\#

65. Shaykhiev, R. et al. Smoking-Induced CXCL14 Expression in the Human Airway Epithelium Links Chronic Obstructive Pulmonary Disease to Lung Cancer.8-15doi:10.1165/rcmb.2012-03960C

66. Kato, A., Hulse, K. E., Tan, B. K. \& Schleimer, R. P. B-lymphocyte lineage cells and the respiratory system. J. Allergy Clin. Immunol. 131, 933-957 (2014).

67. Athari, S. S. Targeting cell signaling in allergic asthma. Signal Transduct. Target. Ther. 1-19 https://doi.org/10.1038/s41392-019-0079-0 (2019).

68. Subrata, L. S. et al. Interactions between Innate Antiviral and Atopic Immunoinflammatory Pathways Precipitate and Sustain Asthma Exacerbations in Children. J Immunol 2009; 1832793-2800 (2009). doi:10.4049/jimmunol.0900695

69. Liao, S., Linderholm, A. L., Yoneda, K. Y., Kenyon, N. J. \& Harper, R. W. Airway transcriptomic profiling after bronchial thermoplasty.1-9(2019). doi:10.1183/23120541.00123-2018

70. Ji, W. \& Rivero, F. Atypical Rho GTPases of the RhoBTB Subfamily: Roles in Vesicle Trafficking and Tumorigenesis. Cells. 5, 28 (2016).

71. Lena, A. M., Cianfarani, F., Odorisio, T., Melino, G. \& Candi, E. MicroRNA-203 contributes to skin reepithelialization.1-7(2012). doi:10.1038/cddis.2012.174

72. Dhar, S. S. et al. Transcriptional Repression of Histone Deacetylase 3 by the Histone Demethylase KDM2A Is Coupled to Tumorigenicity of Lung Cancer Cells *. 289,7483-7496(2014).

73. Turner, S. et al. Variants in genes coding for glutathione S-transferases and asthma outcomes in children. Pharmacogenomics. 19, 707-713 (2018).

74. Wu, Y., Huang, Y., Herring, B. P. \& Gunst, S. J. Integrin-linked kinase regulates smooth muscle differentiation marker gene expression in airway tissue. Am. J. Physiol. Lung Cell. Mol. Physiol. 295, L988-L997 (2008).

75. Rolland, T. \& Tasan, M. C. B. P. S. Z. Q. et al. A proteome-scale map of the human interactome network. Cell. 159, 1213-1226 (2014).

76. Tatsumi, T. et al. MAGE-6 encodes HLA-DRbeta1*0401-presented epitopes recognized by CD4 + T cells from patients with melanoma or renal cell carcinoma. Clin. Cancer Res. 9, 947-954 (2003). 
77. Wieczorek, S., Hellmich, B., Gross, W. L. \& Epplen, J. T. Associations of Churg-Strauss syndrome with the HLA-DRB1 locus, and relationship to the genetics of antineutrophil cytoplasmic antibodyassociated vasculitides: Comment on the article by Vaglio et al [1]. Arthritis Rheum. 58, 329-330 (2008).

78. Gioffredi, A., Maritati, F., Oliva, E. \& Buzio, C. Eosinophilic granulomatosis with polyangiitis: An overview. Front. Immunol. 5, 1-7 (2014).

79. Russell, K. The role of macrophage migration inhibitory factor in airways disease [Doctor of Philosophy Thesis]. Imp. Coll. London(2014).

80. Satish, L. et al. Increased CCT-eta expression is a marker of latent and active disease and a modulator of fibroblast contractility in Dupuytren's contracture. Cell Stress Chaperones. 18, 397-404 (2013).

81. Génier, S. et al. Regulation of GPCR Expression through an interaction with CCT7, a subunit of the CCT/TRiC Complex.Mol. Biol. Cell,3800-3812(2016).

82. Vinayagam, A. et al. W. E. A directed protein interaction network for investigating intracellular signal transduction.Sci. Signal.4(189), (2011).

83. Norton, R. L. \& Hoffmann, P. R. Selenium and asthma. 33, 98-106 (2013).

84. Chen, Y. G. Endocytic regulation of TGF- $\beta$ signaling. Cell Res. 19, 58-70 (2009).

85. Wnuk, D. et al. Enhanced asthma-related fibroblast to myofibroblast transition is the result of profibrotic TGF- $\beta /$ Smad2/3 pathway intensification and antifibrotic TGF- $\beta / S m a d 1 / 5 /(8) 9$ pathway impairment. Sci. Rep. 10, 16492 (2020).

86. Dimasuay, K. G. et al. Parkin, an E3 ubiquitin ligase, enhances airway mitochondrial DNA release and inflammation. Thorax 75, 717 LP - 724(2020).

87. Austin, P. J. et al. Transcriptional profiling identifies the long noncoding RNA plasmacytoma variant translocation (PVT1) as a novel regulator of the asthmatic phenotype in human airway smooth muscle. J. Allergy Clin. Immunol. 139, 780-789 (2014).

88. Arya, P. Functional Characterization of the roles of Endocytic Recycling Regulator EHD1 using in vivo and in vitro analyses. (2015).

89. Pividori, M., Schoettler, N., Nicolae, D. L., Ober, C. \& Im, H. K. Shared and distinct genetic risk factors for childhood-onset and adult-onset asthma: genome-wide and transcriptome-wide studies. Lancet Respir. 7, 509-522 (2019).

90. Standl, M. et al. FADS gene cluster modulates the effect of breastfeeding on asthma. Results from the GINIplus and LISAplus studies. 67,83-90(2012).

91. Sergeant, S. et al. Differences in Arachidonic Acid Levels and Fatty Acid Desaturase (FADS) Gene Variants in African Americans and European Americans with Diabetes/Metabolic Syndrome. Br J Nutr. 107, 547-555 (2012).

92. Fehrenbach, H., Wagner, C. \& Wegmann, M. Airway remodeling in asthma: what really matters. Cell Tissue Res. 367, 551-569 (2017).

93. Frei, N. R. E. S. R. et al. Altered fatty acid metabolism and reduced stearoyl-coenzyme a desaturase activity in asthma.1-9(2017). doi:10.1111/all.13180 
94. Kho, A. T. et al. Circulating MicroRNAs: Association with Lung Function in Asthma. 74, 1-18 (2016).

95. Sabatier, L. et al. Fibrillin-3 expression in human development. Matrix Biol. 30, 43-52 (2011).

96. Corson, G. M., Charbonneau, N. L., Keene, D. R. \& Sakai, L. Y. Differential expression of fibrillin-3 adds to microfibril variety in human and avian, but not rodent. connective tissues. 83, 461-472 (2004).

97. Iwakawa, R. et al. Expression and clinical significance of genes frequently mutated in small cell lung cancers defined by whole exome /. RNA sequencing. 36, 616-621 (2015).

98. Qu, Y. et al. Asthma and the risk of lung cancer: a meta-analysis Table 1 : Characteristics of the included studies. 8,11614-11620(2017).

99. Zong, M. et al. Glucose-6-phosphate isomerase promotes the proliferation and inhibits the apoptosis in fibroblast-like synoviocytes in rheumatoid arthritis. Arthritis Res. Ther.17, (2015).

100. Rolfes, M. C., Juhn, Y. J., Wi, C., Sheen, Y. H. \& Ph, D. Asthma and the Risk of Rheumatoid Arthritis: An Insight into the Heterogeneity and Phenotypes of Asthma. Tuberc. Respir. Dis. (Seoul). 3536, 113-135 (2017).

101. Bs, B. B. W. et al. Proliferation of the Airway Epithelium in Asthma. Are Inflammatory Cells Required. Chest. 123, 384-385 (2001).

102. Li, M. J. et al. GWASdb: a database for human genetic variants identified by genome-wide association studies. 40,1047-1054(2012).

103. Yan, Z., Fedorov, S. A. \& Mumby, M. C. PR48, a Novel Regulatory Subunit of Protein Phosphatase 2A, Interacts with Cdc6 and Modulates DNA Replication. Human Cells. 20, 1021-1029 (2000).

104. Ingram, J. L. \& Kraft, M. Metalloproteinases as modulators of allergic asthma: therapeutic perspectives.61-74(2015).

105. Bergeron, C., Tulic, M. K. \& Hamid, Q. Airway remodelling in asthma: from benchside to clinical practice. Can. Respir. J. 17, e85-93 (2010).

106. Mchugh, B. J., Murdoch, A., Haslett, C. \& Sethi, T. Loss of the Integrin-Activating Transmembrane Protein Fam38A (Piezo1) Promotes a Switch to a Reduced Integrin-DependentMode of Cell Migration.7, (2012).

107. Hill, M. R. et al. A theoretical model of inflammation- and mechanotransduction- driven asthmatic airway remodelling. Biomech. Model. Mechanobiol. 17, 1451-1470 (2018).

108. Seo, G. et al. MAP4K Interactome Reveals STRN4 as a Key STRIPAK Complex Component in Hippo Pathway Regulation. Cell Rep. 32, 107860 (2020).

109. Chuang, H. C. et al. HGK/MAP4K4 deficiency induces TRAF2 stabilization and Th17 differentiation leading to insulin resistance. Nat. Commun. 5, 4602 (2014).

110. Williams, A. E. et al. A. MicroRNA expression profiling in mild asthmatic human airways and effect of corticosteroid therapy. PLoS One. 4, e5889 (2009).

111. Shi, Z., Jiao, S. \& Zhou, Z. STRIPAK complexes in cell signaling and cancer. Oncogene 1-9(2016). doi:10.1038/onc. 2016.9

112. Kim, J., Ham, S. \& Lee, Y. TTC3 contributes to TGF- $\beta 1$-induced epithelial - mesenchymal transition and myo fi broblast differentiation, potentially through SMURF2 ubiquitylation and degradation. Cell 
Death Dis. https://doi.org/10.1038/s41419-019-1308-8 (2019).

113. Tränkner, D., Hahne, N., Sugino, K., Hoon, M. A. \& Zuker, C. Population of sensory neurons essential for asthmatic hyperreactivity of inflamed airways. 111,11515-11520(2014).

114. Al., M. P. et. Genome-wide expression profiling of B lymphocytes reveals IL4R increase in allergic asthma. J ALLERGY CLIN IMMUNOL. 972-975 https://doi.org/10.1016/j.jaci.2014.05.015 (2014).

115. Rieke, F., Lee, A. \& Haeseleer, F. Characterization of Ca2+ -binding protein 5 knockout mouse retina. 49,5126-5135(2010).

116. Lubovac, Z. \& Gustafsson, M. Identification of personalized multi-omic disease modules in asthma. (2018).

117. Pelaia, G. et al. Molecular mechanisms underlying airway smooth muscle contraction and proliferation: Implications for asthma. (2008). doi:10.1016/j.rmed.2008.02.020

118. Chung, A. S., Guan, Y., Yuan, Z., Albina, J. E. \& Chin, Y. E. Ankyrin Repeat and SoCS Box 3 (ASB3) Mediates Ubiquitination and Degradation of Tumor Necrosis Factor Receptor II. 25,4716-4726(2005).

119. Yang, S., Wang, J., Brand, D. D. \& Zheng, S. G. Role of TNF - TNF Receptor 2 Signal in Regulatory T Cells and its Therapeutic implications. 9, (2018).

120. Pernis, A. B. \& Rothman, P. B. JAK-STAT signaling in asthma. 109, 1279-1283 (2002).

121. Signi, A. N. G. et al. Genome-Wide Association Study of Short-Acting beta-2-Agonists. Am. J. Respir. Crit. Care Med. 191, 530-537 (2015).

122. Jones, P., Lucock, M., Scarlett, C. J., Veysey, M. \& Beckett, E. L. Folate and Inflammation - links between folate and features of inflammatory conditions. J. Nutr. Intermed. Metab. https://doi.org/10.1016/j.jnim.2019.100104 (2019).

123. Nicholson, A. et al. Serum folate concentrations, asthma, atopy, and asthma control in Peruvian children. Respir. Med. 133, 29-35 (2017).

124. Li, W. et al. Association of maternal folate intake during pregnancy with infant asthma risk. Sci. Rep. 9, 1-8 (2019).

125. Katula, K. S., Heinloth, A. N. \& Paules, R. S. Folate deficiency in normal human fibroblasts leads to altered expression of genes primarily linked to cell signaling, the cytoskeleton and extracellular matrix. J. Nutr. Chem. 18, 541-552 (2007).

126. Troy, N. M., Hollams, E. M., Holt, P. G. \& Bosco, A. Differential gene network analysis for the identification of asthma-associated therapeutic targets in allergen-specific T-helper memory responses. BMC Med. Genomics. 9, 9 (2016).

127. Luteijn, R. D. et al. SLC19A1 transports immunoreactive cyclic dinucleotides. Nature. 573, 434-438 (2019).

128. Ma, R., Ortiz, T. P., Ridge, K. M., Davis, J. \& Prigge, A. D. The cGAS-STING pathway: The role of self-DNA sensing in inflammatory lung disease.13156-13170(2020). doi:10.1096/fj.202001607R

129. Alam, C. et al. Upregulation of reduced folate carrier by vitamin D enhances brain folate uptake in mice lacking folate receptor alpha. PNAS. 116, 17531-17540 (2019). 
130. Ilan Ifergan, G. \& Jansen, Y. G. A. The Reduced Folate Carrier (RFC) Is Cytotoxic to Cells under Conditions of Severe Folate Deprivation. J. Biol. Chem. 283, 20687-20695 (2008).

131. Dijk, F. N. et al. Genetic regulation of IL1RL1 methylation and IL1RL1-a protein levels in asthma. Eur Respir J51, (2018).

132. Simpkin, A. J. et al. Longitudinal analysis of DNA methylation associated with birth weight and gestational age. Hum. Mol. Genet. 24, 3752-3763 (2015).

133. Mercer, B. A., Lemaître, V., Powell, C. A. \& Armiento, J. D. The Epithelial Cell in Lung Health and Emphysema Pathogenesis. Curr Respir Med Rev. 2, 101-142 (2009).

134. Zhu, Y. M. et al. Z. Y. C14orf159 suppresses gastric cancer cells' invasion and proliferation by inactivating ERK signaling. Cancer Manag Res. 11, 1717-1723 (2019).

135. Poore, G. D. et al. T. E. A miRNA Host Response Signature Accurately Discriminates Acute Respiratory Infection Etiologies. Front Microbiol. 9, 2957 (2018).

136. He, C. et al. Z. X. Identification of the key differentially expressed genes and pathways involved in neutrophilia. Innate Immun. 26, 270-284 (2020).

137. Dopico, X. C. et al. T. J. Widespread seasonal gene expression reveals annual differences in human immunity and physiology. Nat Commun. 6, 7000 (2015).

138. Teleman, A. A., Hietakangas, V. \& Sayadian, A. C. C. S. Nutritional control of protein biosynthetic capacity by insulin via Myc in Drosophila. Cell Metab. 7, 21-32 (2008).

139. Meirelles, S. et al. Cultured Human Adipose Tissue Pericytes and Mesenchymal Stromal Cells Display a Very Similar Gene Expression Profile. Stem Cells Dev. 24, 2822-2840 (2015).

140. Jill, R. et al. Kristian Pietras, Ulf Eriksson, J. F. Pericytes contribute to airway remodeling in a mouse model of chronic allergic asthma. Am J Physiol Lung Cell Mol Physiol. 308, L658-L671 (2015).

141. Riba, M. et al. Revealing the acute asthma ignorome: characterization and validation of uninvestigated gene networks. Nat. Publ. Gr. 1-12, https://doi.org/10.1038/srep24647 (2016).

142. Nguyen, C. et al. Chemogenomic identification of Ref-1/AP-1 as a therapeutic target for asthma. Proc. Natl. Acad. Sci. U. S. A. 100, 1169-1173(2003).

143. Sturrock, A. et al. Nox4 mediates TGF-beta1-induced retinoblastoma protein phosphorylation, proliferation, and hypertrophy in human airway smooth muscle cells. Am. J. Physiol. Lung Cell. Mol. Physiol. 292, L1543-55 (2007).

144. Jia, X. X. et al. Wnt/ $\beta$-catenin signaling pathway regulates asthma airway remodeling by influencing the expression of c-Myc and cyclin D1 via the p38 MAPK-dependent pathway. Exp. Ther. Med. 18, 3431-3438 (2019).

145. Zhang, Y. et al. L. X. HHMD: the human histone modification database.Nucleic Acids Res.38, (2010).

146. Ashburner, M. et al. S. G. Gene ontology: tool for the unification of biology. The Gene Ontology Consortium.Nat. Genet.25, (2000).

147. The Gene Ontology Consortium. The Gene Ontology Resource: 20 years and still GOing strong.Nucleid Acids Res.8, (2019). 
148. Schaefer, C. F. \& Anthony, K. K. S. PID: the Pathway Interaction Database. Nucleic Acids Res. 37, D674-D679 (2009).

149. ENCODE Project Consortium. An integrated encyclopedia of DNA elements in the human genome. Nature. 489, 57-74 (2012).

150. Davis, C. A. et al. C. J. The Encyclopedia of DNA elements (ENCODE): data portal update. Nucleic Acids Res. 46, D794-D801 (2018).

151. Fornes, O. \& Castro-Mondragon, J. A. K. A. JASPAR 2020: update of the open-access database of transcription factor binding profiles. Nucleic Acids Res. (2019). doi:10.1093/nar/gkz1001

152. Lachmann, A. et al. ChEA: transcription factor regulation inferred from integrating genome-wide ChIP-X experiments. Bioinformatics. 26, 2438-2444 (2010).

153. Zhi-Ping Liu, C. \& Wu, H. M. and H. W. RegNetwork: an integrated database of transcriptional and posttranscriptional regulatory networks in human and mouse. Database. https://doi.org/10.1093/database/bav095 (2015).

\section{Tables}

Tab. 1. Curated resources used in gene set enrichment analysis and construction of interaction networks. 


\begin{tabular}{|c|c|}
\hline Interactome & Description \\
\hline \multicolumn{2}{|c|}{ Libraries used for gene set enrichment analysis } \\
\hline $\begin{array}{l}\text { ENCODE } \\
\text { histone } \\
\text { modifications }\end{array}$ & $\begin{array}{l}\text { Database of histone modification probed by ChIP-seq, ChIP-chip and qChIP } \\
\text { studies }^{145}\end{array}$ \\
\hline $\begin{array}{l}\text { GO Biological } \\
\text { process }\end{array}$ & $\begin{array}{l}\text { Library of gene associated with biological programs accomplished by multiple } \\
\text { molecular activities }{ }^{146,147}\end{array}$ \\
\hline $\begin{array}{l}\text { GO molecular } \\
\text { function }\end{array}$ & Library of genes associated with molecular-level activities ${ }^{146,147}$ \\
\hline PID & $\begin{array}{l}\text { The Pathway Interaction Database collection of curated and peer-reviewed } \\
\text { pathways composed of human molecular signaling and regulatory events and key } \\
\text { cellular processes }{ }^{148}\end{array}$ \\
\hline \multicolumn{2}{|c|}{ Interactomes used for network construction } \\
\hline ENCODE & $\begin{array}{l}\text { Transcription factor and gene target data derived from the ENCODE ChIP-seq } \\
\text { data } 149,150\end{array}$ \\
\hline JASPAR & $\begin{array}{l}\text { Transcription factor targets derived from the JASPAR TF binding site profile } \\
\text { database }{ }^{151}\end{array}$ \\
\hline ChEA & $\begin{array}{l}\text { Transcription factor targets database inferred from integrating literature curated } \\
\text { Chip- } X \text { data }^{152}\end{array}$ \\
\hline $\begin{array}{l}\text { TF-miRNA } \\
\text { coregulatory } \\
\text { interactions }\end{array}$ & RegNetwork repository ${ }^{153}$ \\
\hline
\end{tabular}

Tab. 2. Sample's demographics and clinical features. 


\begin{tabular}{|c|c|c|c|}
\hline Characteristic & EA group & Non-EA group & $\begin{array}{l}\text { Difference } \\
\text { p-value }\end{array}$ \\
\hline Sample size & $N=20$ & $N=20$ & $\mathrm{n} / \mathrm{a}^{*}$ \\
\hline Gender, \%female & $13(65 \%)$ & $16(80 \%)$ & 0.240 \\
\hline Age, years ${ }^{\star \star}$ & $58(16)$ & $52(23)$ & 0.096 \\
\hline BMI, $\mathrm{kg} / \mathrm{m}^{2 \star \star}$ & $25.4(3.1)$ & $30.4(11.4)$ & 0.020 \\
\hline Atopy, N (\%) & $11(58 \%)$ & $9(53 \%)$ & 0.515 \\
\hline Allergic rhinitis, $\mathrm{N}(\%)$ & $15(88 \%)$ & $17(89 \%)$ & 0.655 \\
\hline $\begin{array}{l}\text { Gastroesophageal reflux } \\
\text { disease, } N(\%)\end{array}$ & $8(44 \%)$ & $10(58 \%)$ & 0.305 \\
\hline Nicotinism, current, N (\%) & $0(0 \%)$ & $3(18 \%)$ & 0.114 \\
\hline Nicotinism, past, N (\%) & $13(65 \%)$ & $16(80 \%)$ & 0.563 \\
\hline ACT, points $* \star$ & $14(8)$ & $16(9)$ & 0.227 \\
\hline GINA, class (mode) & $4(45 \%)$ & $3(40 \%)$ & 0.569 \\
\hline $\begin{array}{l}\text { Severe asthma (GINA class } 4) \text {, } \\
\text { n (\%) }\end{array}$ & $9(45 \%)$ & $7(35 \%)$ & 0.519 \\
\hline
\end{tabular}

* not applicable, ** median (interquartile range), *** Mann-Whitney U-test or Pearson's chi-squared tests, where applicable; differences of statistical significance at $<0.05$ are in bold.

Tab. 3. Sample's spirometry and high-resolution computed tomography (HRCT) proxies of airway remodeling.

FEV1 - forced expiratory volume in 1 second, VC - vital capacity, TLC - total lung capacity, RV - residual volume. 


\begin{tabular}{|c|c|c|c|}
\hline Characteristic & EA group & Non-EA group & Difference $p$-value* \\
\hline \multicolumn{4}{|l|}{ Spirometry (with reversibility test) } \\
\hline FEV1, L & $2.1(0.79)$ & $2.28(1.26)$ & 0.196 \\
\hline FEV1, \%predicted & $77.4(40.2)$ & $89.7(31.1)$ & 0.421 \\
\hline VC, L & $3.33(1.78)$ & $3.36(1.11)$ & 0.292 \\
\hline FEV1/VC & $62.86(16.86)$ & $67.8(17.1)$ & 0.267 \\
\hline DFEV1, L & $0.21(0.23)$ & $0.17(0.22)$ & 0.506 \\
\hline DFEV1, \% & $0.118(0.143)$ & $0.07(0.13)$ & 0.419 \\
\hline TLC, L & $6.65(2.13)$ & $5.63(1.51)$ & 0.419 \\
\hline TLC, \% predicted & $114.25(18.5)$ & $111.9(22.5)$ & 0.295 \\
\hline RV\%TLC & $30.63(3.68)$ & $30.45(11.48)$ & 0.913 \\
\hline \multicolumn{4}{|c|}{ High-resolution computed tomography remodeling proxies (at RB1 bronchus) } \\
\hline Wall thickness (mm, average) & $1.216(0.32)$ & $1.078(0.22)$ & 0.033 \\
\hline Lumen diameter ( $\mathrm{mm}$, average) & $2.719(0.84)$ & $2.344(0.47)$ & 0.077 \\
\hline Airway diameter ( $\mathrm{mm}$, average) & $5.238(1.58)$ & $4.593(0.68)$ & 0.044 \\
\hline Wall thickness/airway diameter & $14.692(2.2)$ & $14.817(1.94)$ & 0.879 \\
\hline Wall area $\left(\mathrm{mm}^{2}\right)$ & $25.365(12.81)$ & $18.708(6.56)$ & 0.033 \\
\hline Wall area ratio & $44.24(4.99)$ & $45.290(4.98)$ & 0.676 \\
\hline
\end{tabular}

*Mann-Whitney U-test; differences of statistical significance at $<0.05$ are in bold.

Tab. 4. Sample's serum and bronchoalveolar lavage fluid (BALF) cytokine concentrations, cytology and IgE levels. 


\begin{tabular}{|c|c|c|c|}
\hline $\begin{array}{l}\text { Serum cytokines } \\
(\mathrm{pg} / \mathrm{mL})\end{array}$ & EA group (mean $\pm S D$ ) & Non-EA group (mean $\pm S D$ ) & Difference $p$-value* \\
\hline ADAM33 (ng/mL) & $2.229 \pm 1.612$ & $1.462 \pm 0.944$ & 0.126432 \\
\hline IFN-g & $0.575 \pm 1.406$ & $0.405 \pm 1.355$ & 0.490335 \\
\hline $\mathrm{IL}-4$ & $0.005 \pm 0$ & $0.005 \pm 0$ & 0.989209 \\
\hline $\mathrm{IL}-5$ & $0.005 \pm 0$ & $0.946 \pm 4.210$ & 0.797198 \\
\hline IL -6 & $2.058 \pm 2.059$ & $1.366 \pm 1.508$ & 0.386709 \\
\hline $\mathrm{IL}-10$ & $1.260 \pm 1.074$ & $0.602 \pm 0.807$ & 0.017294 \\
\hline $\mathrm{IL}-12 \mathrm{p} 70$ & $1.941 \pm 3.777$ & $1.255 \pm 2.640$ & 0.946084 \\
\hline $\mathrm{IL}-17 \mathrm{~A}$ & $0.188 \pm 0.579$ & $0.171 \pm 0.450$ & 0.860431 \\
\hline IL -23 & $15.81 \pm 25.11$ & $48.53 \pm 98.36$ & 0.323482 \\
\hline Periostin & $1.284 \pm 3.038$ & $0.329 \pm 0.086$ & $\mathrm{n} / \mathrm{a}^{\star \star}$ \\
\hline \multicolumn{4}{|c|}{ Blood count (cells/ml) } \\
\hline Neutrophils & $3580(2100)$ & $3480(1260)$ & 0.370 \\
\hline Lymphocytes & $2240(1110)$ & $1930(730)$ & 0.132 \\
\hline Eosinophils & $480(880)$ & $140(260)$ & 0.008 \\
\hline Basophils & $40(30)$ & $20(20)$ & 0.012 \\
\hline Monocytes & $700(370)$ & $505(110)$ & 0.020 \\
\hline \multicolumn{4}{|l|}{ Other } \\
\hline $\lg E(\mathrm{IU} / \mathrm{mL})$ & 161 (582) & $32(124)$ & 0.018 \\
\hline
\end{tabular}




\begin{tabular}{|llll|}
\hline $\begin{array}{l}\text { BALF cytokines } \\
(\mathbf{p g} / \mathrm{mL})\end{array}$ & EA group (mean $\pm \mathrm{SD})$ & Non-EA group (mean $\pm S D)$ & Difference p-value* \\
\hline Periostin & $0.741 \pm 0.210$ & $\mathbf{0 . 9 1 1} \pm 0.143$ & $\mathbf{0 . 0 1 0 7 2 1}$ \\
\hline $\mathrm{IL}-4$ & $0.645 \pm 1.832$ & $0.379 \pm 1.276$ & 0.930612 \\
\hline $\mathrm{IL}-5$ & $0.342 \pm 1.509$ & $0.005 \pm 0$ & 0.342113 \\
\hline $\mathrm{IL}-6$ & $0.586 \pm 0.583$ & $0.832 \pm 0.624$ & 0.197439 \\
\hline $\mathrm{IL}-10$ & $0.005 \pm 0$ & $0.005 \pm 0$ & $\mathrm{n} / \mathrm{a}$ \\
\hline $\mathrm{IL}-12 \mathrm{p} 70$ & $0.068 \pm 0.021$ & $0.063 \pm 0.033$ & 0.684814 \\
\hline $\mathrm{IL}-17 \mathrm{~A}$ & $0.005 \pm 0$ & $0.005 \pm 0$ & $\mathrm{n} / \mathrm{a}$ \\
\hline $\mathrm{IL}-23$ & $0.245 \pm 1.076$ & $0.005 \pm 0$ & 0.342113 \\
\hline $\mathrm{IFN}-\mathrm{g}$ & $0.005 \pm 0$ & $0.005 \pm 0$ & $\mathrm{n} / \mathrm{a}$ \\
\hline
\end{tabular}

*Mann-Whitney U-test; differences of statistical significance at a=0.05 are in bold.

**not available

Table 5. Genes differentially expressed in bronchial brush biopsy samples of eosinophilic and noneosinophilic asthma patients.

$\log F C$ - log2 fold change (eosinophilic/non-eosinophilic asthma); p-value is unadjusted. 


\begin{tabular}{|c|c|c|c|c|c|c|}
\hline \multicolumn{2}{|c|}{ Differentially expressed gene } & \multicolumn{2}{|c|}{ Gene statistics } & \multicolumn{3}{|c|}{$\begin{array}{l}\text { Literature coverage by keywords } \\
\text { (papers) }\end{array}$} \\
\hline $\begin{array}{l}\text { gene } \\
\text { symbol }\end{array}$ & gene name & $\log \mathrm{FC}$ & p-value & asthma & inflammation & remodeling \\
\hline LRRN2 & $\begin{array}{l}\text { leucine rich repeat } \\
\text { neuronal } 2\end{array}$ & 0.752832 & 0.000398 & - & - & - \\
\hline DLX3 & $\begin{array}{l}\text { distal-less } \\
\text { homeobox } 3\end{array}$ & 0.7525317 & 0.001541 & - & - & 13 \\
\hline SERP2 & $\begin{array}{l}\text { stress associated } \\
\text { endoplasmic } \\
\text { reticulum protein } \\
\text { family member } 2\end{array}$ & -0.57667 & 0.003001 & - & - & - \\
\hline PYURF & $\begin{array}{l}\text { PIGY upstream } \\
\text { reading frame }\end{array}$ & -0.54608 & 0.003259 & - & - & - \\
\hline RUVBL2 & $\begin{array}{l}\text { RuvB like AAA } \\
\text { ATPase } 2\end{array}$ & -0.53847 & 0.004246 & - & 1 & 47 \\
\hline RAPH1 & $\begin{array}{l}\text { Ras association } \\
\text { (RalGDS/AF-6) and } \\
\text { pleckstrin } \\
\text { homology domains } \\
1\end{array}$ & 0.736463 & 0.004406 & - & - & 5 \\
\hline C1QB & $\begin{array}{l}\text { complement C1q B } \\
\text { chain }\end{array}$ & -0.71181 & 0.005344 & - & - & 3 \\
\hline TMEM207 & $\begin{array}{l}\text { transmembrane } \\
\text { protein } 207\end{array}$ & 0.553981 & 0.005435 & - & - & - \\
\hline DOLK & dolichol kinase & 0.529385 & 0.006096 & - & - & - \\
\hline HCG22 & $\begin{array}{l}\text { HLA complex } \\
\text { group } 22 \\
\text { (gene/pseudogene) }\end{array}$ & 0.536178 & 0.006125 & 1 & - & - \\
\hline CARD6 & $\begin{array}{l}\text { caspase } \\
\text { recruitment domain } \\
\text { family member } 6\end{array}$ & -0.44055 & 0.006864 & - & - & 1 \\
\hline CFAP299 & $\begin{array}{l}\text { cilia and flagella } \\
\text { associated protein } \\
299\end{array}$ & 0.690009 & 0.00689 & - & - & - \\
\hline GNGT1 & $\begin{array}{l}\text { G protein subunit } \\
\text { gamma transducin }\end{array}$ & 0.45062 & 0.007328 & - & - & - \\
\hline GLRA2 & $\begin{array}{l}\text { glycine receptor } \\
\text { alpha } 2\end{array}$ & 0.618096 & 0.0074 & - & - & 2 \\
\hline DTD2 & $\begin{array}{l}\text { D-aminoacyl-tRNA } \\
\text { deacylase } 2\end{array}$ & 0.470056 & 0.00858 & - & - & - \\
\hline
\end{tabular}




\begin{tabular}{|lllllll|} 
KLK15 & $\begin{array}{l}\text { kallikrein related } \\
\text { peptidase 15 }\end{array}$ & 0.475823 & 0.008796 & - & - & 3 \\
\hline SPACA3 & $\begin{array}{l}\text { sperm acrosome } \\
\text { associated 3 }\end{array}$ & -0.68256 & 0.008854 & - & 5 & 3 \\
\hline PEXL1 & $\begin{array}{l}\text { nuclear } \\
\text { transcription factor, } \\
\text { X-box binding like 1 }\end{array}$ & 0.536674 & 0.009328 & - & - & - \\
\hline GTF2E2 & $\begin{array}{l}\text { p53 apoptosis } \\
\text { feffector related to } \\
\text { PMP22 }\end{array}$ & -1.24111 & 0.0097 & - & 2 & 3 \\
\hline $\begin{array}{l}\text { general } \\
\text { transcription factor } \\
\text { IIE subunit 2 }\end{array}$ & 0.496494 & 0.009859 & - & - & - \\
\hline
\end{tabular}

Table 6. Genes differentially co-expressed in bronchial brush biopsy samples of eosinophilic and noneosinophilic asthma patients. logFC - log2 fold change (eosinophilic/non-eosinophilic asthma). All pvalues for differential expression $\geq 0.01$. 


\begin{tabular}{|c|c|c|c|c|c|}
\hline \multicolumn{2}{|c|}{$\begin{array}{l}\text { Differentially } \\
\text { co-expressed genes }\end{array}$} & \multirow{2}{*}{$\begin{array}{l}\text { Gene statistics } \\
\text { logFC }\end{array}$} & \multicolumn{3}{|c|}{$\begin{array}{l}\text { Literature coverage by keywords } \\
\text { (papers) }\end{array}$} \\
\hline gene symbol & Entrez ID & & asthma & inflammation & remodeling \\
\hline \multicolumn{6}{|c|}{ Up-regulated in eosinophilic asthma } \\
\hline ATP1B1 & 481 & 0.533982929 & 1 & 1 & 8 \\
\hline STRN4 & 29888 & 0.480691965 & - & - & - \\
\hline GPI & 2821 & 0.348522395 & - & 16 & 33 \\
\hline ANKRD26P1 & 124149 & 0.259044209 & - & - & - \\
\hline RAPH1 & 65059 & 0.24468644 & - & - & 5 \\
\hline RP3-473B4.3 & 340581 & 0.145016395 & - & - & - \\
\hline CLC & 1178 & 0.123772953 & 5 & 75 & 9 \\
\hline RADX & 55086 & 0.107286105 & - & - & - \\
\hline RECK & 8434 & 0.083728976 & 1 & 1 & 45 \\
\hline C14orf159 & 80017 & 0.076215968 & - & - & - \\
\hline SLC19A1 & 6573 & 0.067933101 & 1 & & 5 \\
\hline TTC3P1 & 286495 & 0.060221639 & - & - & - \\
\hline RP11-321E2.2 & 202201 & 0.052235123 & - & - & - \\
\hline MAEA & 10296 & 0.048993296 & 1 & 4 & 8 \\
\hline FBN3 & 84467 & 0.034589284 & - & & 1 \\
\hline PSG2 & 5670 & 0.030748795 & - & 1 & 3 \\
\hline PPP2R3B & 28227 & 0.024124236 & - & - & - \\
\hline GOLGA2P3Y & 84559 & 0.023073362 & - & - & - \\
\hline STOML3 & 161003 & 0.024668921 & - & - & - \\
\hline DIO3 & 1735 & 0.018910174 & - & - & 6 \\
\hline FADS6 & 283985 & 0.017092506 & - & - & - \\
\hline EPS8L1 & 54869 & 0.011524955 & - & - & 1 \\
\hline RPS13 & 85388 & 0.013323104 & - & - & 1 \\
\hline ASB3 & 388949 & 0.00830234 & - & - & 1 \\
\hline MRPL14 & 64928 & 0.008790486 & - & - & - \\
\hline
\end{tabular}




\begin{tabular}{|llllll|}
\hline EPS15 & 2060 & -0.004142139 & - & - & 3 \\
RHOBTB2 & 23221 & -0.010079354 & - & - & - \\
\hline SRCRB4D & 136853 & -0.01620345 & - & - & - \\
\hline OR52I1 & 390037 & -0.097623097 & - & - & 4 \\
CCT7 & 10574 & -0.141075317 & - & - & - \\
\hline SRPRB & 58477 & -0.161702668 & - & - & - \\
\hline CABP5 & 51476 & -0.601734939 & - & - & \\
\hline
\end{tabular}

Tab. 7. Cell-type enrichment analysis of histone ChIP-seq peak marks of human cell lines annotated within the Encyclopedia of DNA Elements (ENCODE).

Note: adjusted p-values $>0.05$. 


\begin{tabular}{|c|c|c|}
\hline Histone modification and cell line & p-value & Affected genes \\
\hline H3K9ac fibroblast of lung hg19 & 0.035726 & $\begin{array}{l}\text { ASB3; RADX; CCT7; MRPL14; PPP2R3B; RPS13; } \\
\text { SLC19A1 }\end{array}$ \\
\hline H3K27me3 fibroblast of lung hg19 & 0.045305 & $\begin{array}{l}\text { CLC; RADX; DIO3; EPS8L1; FADS6; FBN3; } \\
\text { SLC19A1; SRCRB4D; STOML3 }\end{array}$ \\
\hline H3K36me3 myocyte mm9 & 0.054552 & ASB3;RPS13 \\
\hline H3K27me3 SK-N-SH hg19 & 0.122431 & FBN3;FADS6;EPS8L1;DIO3;CLC;RADX \\
\hline H3K9ac K562 hg19 & 0.166164 & $\begin{array}{l}\text { FADS6;RAPH1;MRPL14;PPP2R3B;CCT7; } \\
\text { ATP1B1;SRCRB4D;SLC19A1 }\end{array}$ \\
\hline H3K4me1 G1E mm9 & 0.209147 & $\begin{array}{l}\text { FADS6;RAPH1;EPS8L1;SRPRB;SRCRB4D; } \\
\text { RECK }\end{array}$ \\
\hline H3K9me3 A549 hg19 & 0.211366 & $\begin{array}{l}\text { CABP5;ANKRD26P1;TTC3P1;DIO3; } \\
\text { ATP1B1 }\end{array}$ \\
\hline $\begin{array}{l}\text { H3K4me1 CD14-positive monocyte } \\
\text { hg19 }\end{array}$ & 0.211366 & GPI;FADS6;EPS8L1;CCT7;RECK \\
\hline $\begin{array}{l}\text { H2AFZ skeletal muscle myoblast } \\
\text { hg19 }\end{array}$ & 0.211366 & FADS6;RAPH1;ASB3;SLC19A1;RHOBTB2 \\
\hline H3K9ac mammary epithelial cell hg19 & 0.211366 & EPS8L1;MRPL14;PPP2R3B;ASB3;RHOBTB2 \\
\hline $\begin{array}{l}\text { H3K27me3 T-cell acute lymphoblastic } \\
\text { leukemia hg19 }\end{array}$ & 0.211366 & GPI;STOML3;EPS8L1;SRCRB4D;STRN4 \\
\hline H3K27ac HepG2 hg19 & 0.211366 & GPI;MAEA;RADX;CCT7;RPS13 \\
\hline H3K27ac GM12878 hg19 & 0.211366 & RAPH1;PPP2R3B;CCT7;ATP1B1;SLC19A1 \\
\hline $\begin{array}{l}\text { H3K4me3 skeletal muscle myoblast } \\
\text { hg19 }\end{array}$ & 0.211366 & MRPL14;PPP2R3B;RADX;CCT7;RPS13 \\
\hline H3K27ac astrocyte hg19 & 0.211366 & C14ORF159;ASB3;STRN4;RPS13;RHOBTB2 \\
\hline H3K27me3 myotube hg19 & 0.211366 & FBN3;CABP5;EPS8L1;CLC;SRCRB4D \\
\hline H3K9me1 keratinocyte hg19 & 0.211366 & GPI;MAEA;CCT7;RECK;STRN4 \\
\hline $\begin{array}{l}\text { H3K9ac CD14-positive monocyte } \\
\text { hg19 }\end{array}$ & 0.211366 & RAPH1;EPS8L1;MRPL14;PPP2R3B;CCT7 \\
\hline
\end{tabular}

Tab. 8. Biological processes associated with genes differentially co-expressed between eosinophilic and non-eosinophilic asthma in bronchial brush biopsy samples.

Gene ontology derived from GO Biological Process 2018 by Gene Ontology Consortium.

Note: adjusted $p$-values $>0.05$. 


\begin{tabular}{|c|c|c|c|c|c|}
\hline Biological process & $\begin{array}{l}\text { Accession } \\
\text { number }\end{array}$ & Genes & $\mathrm{p}$-value & $\begin{array}{l}\text { z- } \\
\text { score }\end{array}$ & $\begin{array}{l}\text { combined } \\
\text { log(p- } \\
\text { value)*z- } \\
\text { score }\end{array}$ \\
\hline \multirow[t]{2}{*}{ Rho protein signal transduction } & GO:0007266 & EPS8L1 & 0.00591 & -39.98 & 89.1 \\
\hline & & RHOBTB2 & & & \\
\hline regulation of $\mathrm{T}$ cell tolerance induction & G0:0002664 & CLC & 0.00956 & -239.9 & 484 \\
\hline $\begin{array}{l}\text { negative regulation of myeloid cell } \\
\text { apoptotic process }\end{array}$ & G0:0033033 & MAEA & 0.00956 & -239.9 & 484 \\
\hline $\begin{array}{l}\text { regulation of cytokine production } \\
\text { involved in immune response }\end{array}$ & GO:0002718 & CLC & 0.00956 & -239.9 & 484 \\
\hline hemostasis & GO:0007599 & GPI & 0.01115 & -205.6 & 401 \\
\hline folic acid transport & G0:0015884 & SLC19A1 & 0.01115 & -205.6 & 401 \\
\hline $\begin{array}{l}\text { positive regulation of protein } \\
\text { localization to Cajal body }\end{array}$ & GO:1904871 & CCT7 & 0.01273 & -179.9 & 341 \\
\hline $\begin{array}{l}\text { regulation of protein localization to } \\
\text { Cajal body }\end{array}$ & GO:1904869 & СCT7 & 0.01273 & -179.9 & 341 \\
\hline regulation of $\mathrm{T}$ cell mediated immunity & G0:0002709 & CLC & 0.01273 & -179.9 & 341 \\
\hline $\begin{array}{l}\text { positive regulation of establishment of } \\
\text { protein localization to telomere }\end{array}$ & GO:1904851 & CCT7 & 0.01431 & -159.9 & 295 \\
\hline $\begin{array}{l}\text { regulation of immunoglobulin } \\
\text { secretion }\end{array}$ & G0:0051023 & GPI & 0.01431 & -159.9 & 295 \\
\hline $\begin{array}{l}\text { positive regulation of immunoglobulin } \\
\text { secretion }\end{array}$ & GO:0051024 & GPI & 0.01431 & -159.9 & 295 \\
\hline $\begin{array}{l}\text { potassium ion import across plasma } \\
\text { membrane }\end{array}$ & GO:1990573 & ATP1B1 & 0.01431 & -159.9 & 295 \\
\hline thyroid hormone generation & GO:0006590 & DIO3 & 0.01589 & -143.9 & 259 \\
\hline $\begin{array}{l}\text { regulation of establishment of protein } \\
\text { localization to telomere }\end{array}$ & G0:0070203 & CCT7 & 0.01589 & -143.9 & 259 \\
\hline $\begin{array}{l}\text { cardiac muscle cell membrane } \\
\text { repolarization }\end{array}$ & G0:0099622 & ATP1B1 & 0.01746 & -130.8 & 230 \\
\hline $\begin{array}{l}\text { membrane repolarization during action } \\
\text { potential }\end{array}$ & GO:0086011 & ATP1B1 & 0.01746 & -130.8 & 230 \\
\hline import across plasma membrane & $\begin{array}{r}\text { GO:0098739 } \\
\text { Page } 44 / 60\end{array}$ & ATP1B1 & 0.01746 & -130.8 & 230 \\
\hline
\end{tabular}




\begin{tabular}{|llllll|}
\hline relaxation of muscle & GO:0090075 & ATP1B1 & 0.01746 & -130.8 & 230 \\
\hline $\begin{array}{l}\text { positive regulation of sodium ion } \\
\text { transmembrane transporter activity }\end{array}$ & G0:2000651 & ATP1B1 & 0.01746 & -130.8 & 230
\end{tabular}

\begin{tabular}{|llllll|}
\hline relaxation of cardiac muscle & G0:0055119 & ATP1B1 & 0.01746 & -130.8 & 230 \\
\hline $\begin{array}{l}\text { positive regulation of protein } \\
\text { ocalization to chromosome, telomeric } \\
\text { region }\end{array}$ & G0:1904816 & CCT7 & 0.01746 & -130.8 & 230 \\
\hline
\end{tabular}

$\begin{array}{llllll}\begin{array}{l}\text { positive regulation of potassium ion } \\ \text { transmembrane transporter activity }\end{array} & \text { GO:1901018 } & \text { ATP1B1 } & 0.01904 & -119.9 & 206\end{array}$

$\begin{array}{llllll}\begin{array}{l}\text { positive regulation of establishment of } \\ \text { protein localization }\end{array} & \text { GO:1904951 } & \text { CCT7 } & 0.01904 & -119.9 & 206\end{array}$
$\begin{array}{llllll}\text { positive regulation of ruffle assembly } & \text { G0:1900029 } & \text { EPS8L1 } & 0.01904 & -119.9 & 206\end{array}$

\begin{tabular}{lllllll}
\hline sodium ion export & G0:0071436 & ATP1B1 & 0.02061 & -110.7 & 187 \\
\hline cellular potassium ion homeostasis & G0:0030007 & ATP1B1 & 0.02061 & -110.7 & 187 \\
\hline sodium ion export from cell & G0:0036376 & ATP1B1 & 0.02061 & -110.7 & 187
\end{tabular}

$\begin{array}{llllll}\text { regulation of T cell cytokine production } & \text { GO:0002724 } & \text { CLC } & 0.02061 & -110.7 & 187\end{array}$

\begin{tabular}{|llllll}
\hline membrane repolarization & GO:0086009 & ATP1B1 & 0.02061 & -110.7 & 187 \\
\hline transmembrane transport & GO:0055085 & STOML3 & 0.02215 & -11.42 & 18.9
\end{tabular}

ATP1B1

SLC19A1

$\begin{array}{llllll}\text { modified amino acid transport } \quad \text { GO:0072337 } & \text { SLC19A1 } & 0.02218 & -102.8 & 170\end{array}$

$\begin{array}{llllll}\text { cell communication by electrical } & \text { G0:0086064 } & \text { ATP1B1 } & 0.02218 & -102.8 & 170\end{array}$ coupling involved in cardiac conduction

\begin{tabular}{|llllll|}
\hline clathrin coat assembly & G0:0048268 & EPS15 & 0.02218 & -102.8 & 170 \\
\hline $\begin{array}{l}\text { establishment or maintenance of actin } \\
\text { cytoskeleton polarity }\end{array}$ & G0:0030950 & RHOBTB2 & 0.02218 & -102.8 & 170
\end{tabular}


localization to Cajal body

\begin{tabular}{llllll}
\hline amide transport & G0:0042886 & SLC19A1 & 0.02374 & -95.94 & 156 \\
\hline cofactor transport & G0:0051181 & SLC19A1 & 0.02374 & -95.94 & 156 \\
\hline cellular sodium ion homeostasis & G0:0006883 & ATP1B1 & 0.02374 & -95.94 & 156 \\
\hline $\begin{array}{l}\text { negative regulation of RNA metabolic } \\
\text { process }\end{array}$ & G0:0051253 & RPS13 & 0.02374 & -95.94 & 156 \\
$\begin{array}{l}\text { membrane repolarization during } \\
\text { cardiac muscle cell action potential }\end{array}$ & G0:0086013 & ATP1B1 & 0.02374 & -95.94 & 156 \\
\hline & & & & &
\end{tabular}

positive regulation of potassium ion transmembrane transport

GO:1901381 ATP1B1 $\quad 0.02374 \quad-95.94 \quad 156$

protein stabilization

GO:0050821 CCT7

$0.02452 \quad-18.94 \quad 30.5$

ATP1B1

cellular monovalent inorganic cation homeostasis

G0:0030004 ATP1B1 $0.02687 \quad-84.65 \quad 133$

positive regulation of calcium ion

transmembrane transporter activity

$\begin{array}{lllll}\text { GO:1901021 } & \text { ATP1B1 } & 0.02687 & -84.65 & 133\end{array}$

viral entry into host cell

regulation of cellular response to growth factor stimulus

negative regulation of RNA splicing

regulation of telomerase RNA

localization to Cajal body

drug transport

folic acid metabolic process

positive regulation of immunoglobulin production

Golgi to endosome transport

regulation of ruffle assembly

\begin{tabular}{lllll} 
G0:0046718 & EPS15 & 0.02687 & -84.65 & 133 \\
\hline G0:0090287 & FBN3 & 0.02842 & -79.95 & 124
\end{tabular}

GO:0033119 RPS13

0.02842

$-79.95 \quad 124$

GO:1904872 CCT7

$\begin{array}{lll}0.02842 & -79.95 & 124\end{array}$

G0:0015893

SLC19A1

0.02998

$-75.74 \quad 115$

GO:0046655

SLC19A1

0.02998

$-75.74 \quad 115$

GO:0002639 GPI

$0.02998 \quad-75.74 \quad 115$

GO:0006895 EPS15

0.03153

$-71.96$

108

GO:1900027 EPS8L1

0.03308

$-68.53$

101 
regulation of cardiac muscle

contraction by calcium ion signaling

vitamin transport

folic acid-containing compound metabolic process

positive regulation of ion

transmembrane transporter activity

glycolytic process through glucose-6phosphate

canonical glycolysis

regulation of potassium ion

transmembrane transporter activity

potassium ion homeostasis

glucose catabolic process to pyruvate

sodium ion homeostasis

endocytic recycling

regulation of actin polymerization or depolymerization

cardiac muscle cell action potential

dicarboxylic acid transport

regulation of activated $\mathrm{T}$ cell proliferation

regulation of protein polymerization

ion transmembrane transport

Ras protein signal transduction

positive regulation of telomere maintenance via telomerase

purine ribonucleoside triphosphate metabolic process
GO:0010882 ATP1B1 $0.03308 \quad-68.53 \quad 101$

G0:0051180 SLC19A1 $0.03618 \quad-62.57 \quad 90.2$

G0:0006760 SLC19A1 $0.03618 \quad-62.57 \quad 90.2$

G0:0032414 ATP1B1 $\quad 0.03618 \quad-62.57 \quad 90.2$

GO:0061620 GPI

$0.03926 \quad-57.56 \quad 80.9$

GO:0061621 GPI

$0.03926 \quad-57.56 \quad 80.9$

GO:1901016 ATP1B1

$\begin{array}{lll}0.03926 & -57.56 \quad 80.9\end{array}$

GO:0055075

ATP1B1

0.03926

$-57.56$

80.9

GO:0061718 GPI

0.03926

$-57.56$

80.9

G0:0055078

ATP1B1

0.0408

$-55.35$

76.9

G0:0032456 EPS15

0.04234

$-53.3$

73.2

GO:0008064

EPS8L1

$0.04387 \quad-51.4$

69.8

G0:0086001

ATP1B1

0.04541

$-49.62$

66.6

G0:0006835

SLC19A1

0.04541

$-49.62$

66.6

G0:0046006 CLC

0.04541

$-49.62$

66.6

GO:0032271

EPS8L1

0.04694

$-47.97$

63.7

STOML3

0.04775

$-13.14$

17.4

ATP1B1

G0:0007265

EPS8L1

0.04932

$-12.91$

16.9

RHOBTB2

GO:0032212 CCT7

0.04999

$-44.97$

58.5

GO:0009205

ATP1B1

0.04999

$-44.97$

58.5 
Tab. 9. Molecular functions associated with genes differentially co-expressed between eosinophilic and non-eosinophilic asthma in bronchial brush biopsy samples.

Gene ontology derived from GO Molecular Function 2018 by Gene Ontology Consortium.

Note: adjusted p-values $>0.05$.

\begin{tabular}{|c|c|c|c|c|c|}
\hline Molecular function & $\begin{array}{l}\text { Accession } \\
\text { number }\end{array}$ & Genes & p-value & z-score & $\begin{array}{l}\text { combined } \\
\text { log(p- } \\
\text { value)*z- } \\
\text { score }\end{array}$ \\
\hline $\mathrm{T}$ cell receptor binding & G0:0042608 & EPS8L1 & 0.00956 & -239.85 & 484.4 \\
\hline small ribosomal subunit rRNA binding & GO:0070181 & RPS13 & 0.01115 & -205.59 & 401.5 \\
\hline signal recognition particle binding & GO:0005047 & SRPRB & 0.01273 & -179.89 & 340.9 \\
\hline armadillo repeat domain binding & GO:0070016 & STRN4 & 0.01431 & -159.9 & 294.9 \\
\hline potassium-transporting ATPase activity & G0:0008556 & ATP1B1 & 0.01746 & -130.83 & 230 \\
\hline $\begin{array}{l}\text { sodium:potassium-exchanging ATPase } \\
\text { activity }\end{array}$ & G0:0005391 & ATP1B1 & 0.01746 & -130.83 & 230 \\
\hline sodium ion binding & GO:0031402 & ATP1B1 & 0.01904 & -119.93 & 206.3 \\
\hline metalloendopeptidase inhibitor activity & GO:0008191 & RECK & 0.01904 & -119.93 & 206.3 \\
\hline potassium ion binding & G0:0030955 & ATP1B1 & 0.01904 & -119.93 & 206.3 \\
\hline $\begin{array}{l}\text { Rac guanyl-nucleotide exchange factor } \\
\text { activity }\end{array}$ & G0:0030676 & EPS8L1 & 0.02218 & -102.79 & 170 \\
\hline alkali metal ion binding & G0:0031420 & ATP1B1 & 0.0253 & -89.945 & 143.6 \\
\hline MHC class II protein complex binding & GO:0023026 & ATP1B1 & 0.0253 & -89.945 & 143.6 \\
\hline $\begin{array}{l}\text { cysteine-type endopeptidase activity } \\
\text { involved in apoptotic process }\end{array}$ & GO:0097153 & CLC & 0.0253 & -89.945 & 143.6 \\
\hline MHC protein complex binding & GO:0023023 & ATP1B1 & 0.02998 & -75.743 & 115.4 \\
\hline lysophospholipase activity & G0:0004622 & CLC & 0.02998 & -75.743 & 115.4 \\
\hline protein phosphatase $2 \mathrm{~A}$ binding & GO:0051721 & STRN4 & 0.03153 & -71.956 & 108 \\
\hline mRNA 5'-UTR binding & GO:0048027 & RPS13 & 0.03463 & -65.414 & 95.5 \\
\hline ATPase activator activity & GO:0001671 & ATP1B1 & 0.03618 & -62.57 & 90.2 \\
\hline
\end{tabular}

Tab. 10. Impact of kinase perturbations in animal studies on genes differentially expressed between eosinophilic and non-eosinophilic asthma in bronchial brush biopsy samples. Kinase perturbation studies 
data retrieved from Gene Expression Omnibus using Enrichr software. Only terms with p-value $<0.05$ are shown; p-values adjusted by Fisher's exact test $>0.05$.

\begin{tabular}{|llllll|}
\hline $\begin{array}{l}\text { Affected kinase } \\
\text { and study type }\end{array}$ & $\begin{array}{l}\text { GEO accession } \\
\text { number }\end{array}$ & $\begin{array}{l}\text { Affected } \\
\text { genes }\end{array}$ & $\begin{array}{l}\text { p- } \\
\text { value }\end{array}$ & $\begin{array}{l}\text { Z- } \\
\text { score }\end{array}$ & $\begin{array}{l}\text { combined } \\
\text { log(p- } \\
\text { value) } \\
\text { *Z-score }\end{array}$ \\
\hline Genes up-regulated due to kinase perturbation & GSE39253 & GPI & 0.0120 & -14.39 & 27.63348 \\
\hline $\begin{array}{l}\text { HIPK1 } \\
\text { (knockout) }\end{array}$ & MAEA & & & \\
\hline TGFBR2 (knockout) & GSE22989 & MRPL14 & 0.0120 & -14.39 & 27.63348 \\
& & CCT7 & & & \\
\hline $\begin{array}{l}\text { Genes down-regulated due to kinase perturbation } \\
\text { GSE27869 }\end{array}$ & EPS15 & & & \\
\hline $\begin{array}{l}\text { IKBKE } \\
\text { (siRNA-mediated } \\
\text { knockdown) }\end{array}$ & C14ORF159 & 0.0120 & -14.39 & 27.63348 \\
\hline & RAPH1 & & & \\
\hline
\end{tabular}

Tab. 11. Signaling pathways associated with transcription factors from the regulatory network of genes differentially co-expressed between eosinophilic and non-eosinophilic asthma in bronchial brush biopsy samples. 


\begin{tabular}{|c|c|c|c|c|c|}
\hline Signaling pathway & Genes & p-value & q-value & $\begin{array}{l}\text { z- } \\
\text { score }\end{array}$ & $\begin{array}{l}\text { combined } \\
\text { log(p-value) } \\
\text { *z-score }\end{array}$ \\
\hline $\begin{array}{l}\text { Regulation of } \\
\text { nuclear SMAD2/3 } \\
\text { signaling }\end{array}$ & $\begin{array}{l}\text { CEBPB; HDAC1; GATA3; } \\
\text { NR3C1; FOXO3; SIN3B; } \\
\text { HNF4A; MYC; EP300; E2F4; } \\
\text { E2F5; SMAD2; JUN; } \\
\text { SMAD4; SMAD3; VDR; } \\
\text { TFE3; ESR1; RUNX2; } \\
\text { RUNX1; AR; NCOR1; CREB1; } \\
\text { TFDP1; SP1; SP3; TCF3; } \\
\text { ATF3 }\end{array}$ & 8.73E-37 & $1.82 \mathrm{E}-34$ & -83.78 & 3021.193231 \\
\hline $\begin{array}{l}\text { AP-1 transcription } \\
\text { factor network }\end{array}$ & $\begin{array}{l}\text { EGR1; JUN; NR3C1; GATA2; } \\
\text { ETS1; HIF1A; ESR1; FOSL1; } \\
\text { CREB1; CCND1; SP1; MYC; } \\
\text { EP300; CTNNB1; TP53; } \\
\text { ATF3 }\end{array}$ & $2.86 \mathrm{E}-18$ & 2.99E-16 & -56.20 & 986.0307212 \\
\hline $\begin{array}{l}\text { E2F transcription } \\
\text { factor network }\end{array}$ & $\begin{array}{l}\text { HDAC1; TFE3; BRCA1; HIC1; } \\
\text { YY1; TFDP1; TRIM28; SP1; } \\
\text { MYC; E2F1;EP300; MYBL2; } \\
\text { HBP1; E2F4; E2F5; E2F6 }\end{array}$ & $6.00 \mathrm{E}-18$ & 4.18E-16 & -53.86 & 927.6012899 \\
\hline $\begin{array}{l}\text { Notch-mediated } \\
\text { HES/HEY network }\end{array}$ & $\begin{array}{l}\text { HDAC1; STAT3; ARNT; } \\
\text { GATA4; RBPJ; HIF1A; } \\
\text { GATA1; RUNX2; YY1; AR; } \\
\text { NCOR1; E2F1; EP300; TCF3 }\end{array}$ & $1.09 \mathrm{E}-17$ & $5.70 \mathrm{E}-16$ & -70.69 & 1199.092417 \\
\hline $\begin{array}{l}\text { Validated targets } \\
\text { of C-MYC } \\
\text { transcriptional } \\
\text { repression }\end{array}$ & $\begin{array}{l}\text { SMAD2; SMAD4; SPI1; } \\
\text { SMAD3; NFYA; HDAC1; } \\
\text { NFYC; BRCA1; FOXO3; } \\
\text { CREB1; CCND1; SP1; MYC; } \\
\text { EP300 }\end{array}$ & $7.48 \mathrm{E}-16$ & 3.13E-14 & -53.86 & 814.7221182 \\
\hline $\begin{array}{l}\text { Glucocorticoid } \\
\text { receptor regulatory } \\
\text { network }\end{array}$ & $\begin{array}{l}\text { EGR1; JUN; SPI1; HDAC1; } \\
\text { GATA3; NR3C1; RELA; } \\
\text { NFKB1; PBX1; SMARCA4; } \\
\text { NR4A1; CREB1; IRF1; } \\
\text { EP300; TP53 }\end{array}$ & $1.51 \mathrm{E}-15$ & 5.27E-14 & -44.34 & 657.0726358 \\
\hline $\begin{array}{l}\text { Regulation of } \\
\text { nuclear beta } \\
\text { catenin signaling } \\
\text { and target gene } \\
\text { transcription }\end{array}$ & $\begin{array}{l}\text { JUN; HDAC1; LEF1; MITF; } \\
\text { KLF4; SMARCA4; AR; } \\
\text { CCND1; MYC; SALL4; } \\
\text { EP300; CTNNB1; HBP1; } \\
\text { TCF4 }\end{array}$ & $2.18 \mathrm{E}-14$ & $6.51 \mathrm{E}-13$ & -42.95 & 586.7956942 \\
\hline $\begin{array}{l}\text { Regulation of } \\
\text { retinoblastoma } \\
\text { protein }\end{array}$ & $\begin{array}{l}\text { CEBPB; JUN; SPI1; HDAC1; } \\
\text { MITF; RUNX2; SMARCA4; } \\
\text { TFDP1; CCND1;E2F1; } \\
\text { EP300; PPARG; E2F4 }\end{array}$ & 2.92E-14 & 7.62E-13 & -49.23 & 666.3598742 \\
\hline $\begin{array}{l}\text { Regulation of } \\
\text { Telomerase }\end{array}$ & $\begin{array}{l}\text { JUN; SMAD3; HDAC1; ESR1; } \\
\text { NFKB1; CCND 1; SIN3B; } \\
\text { WT1; SP1; MYC; IRF1; SP3; } \\
\text { E2F1 }\end{array}$ & $5.50 \mathrm{E}-14$ & $1.28 \mathrm{E}-12$ & -47.03 & 623.584993 \\
\hline $\begin{array}{l}\text { FOXA1 } \\
\text { transcription factor }\end{array}$ & $\begin{array}{l}\text { FOXA1; AR; CEBPB; JUN; } \\
\text { NFIA; SP1; NFIC; EP300; }\end{array}$ & $2.48 \mathrm{E}-13$ & $5.18 \mathrm{E}-12$ & -60.59 & 763.8201229 \\
\hline
\end{tabular}




\begin{tabular}{|c|c|c|c|c|c|}
\hline network & BRCA1; ESR1; FOXA2 & & & & \\
\hline $\begin{array}{l}\text { C-MYB } \\
\text { transcription factor } \\
\text { network }\end{array}$ & $\begin{array}{l}\text { CEBPB; SPI1; NCOR1; } \\
\text { CCND1; TRIM28; SP1; MYC; } \\
\text { LEF1; EP300; GATA3; ETS1; } \\
\text { GATA1 }\end{array}$ & 1.77E-11 & 3.36E-10 & -35.47 & 381.3941217 \\
\hline $\begin{array}{l}\text { Validated nuclear } \\
\text { estrogen receptor } \\
\text { alpha network }\end{array}$ & $\begin{array}{l}\text { CEBPB; JUN; SMAD4; } \\
\text { NCOR1; CCND 1; HDAC1; } \\
\text { MYC; EP300; BRCA1; ESR1; } \\
\text { ESR2 }\end{array}$ & $2.04 \mathrm{E}-11$ & $3.55 \mathrm{E}-10$ & -41.66 & 445.3469976 \\
\hline $\begin{array}{l}\text { Signaling events } \\
\text { mediated by HDAC } \\
\text { Class I }\end{array}$ & $\begin{array}{l}\text { YY1; NCOR1; SIN3B; } \\
\text { HDAC1; STAT3; EP300; } \\
\text { PPARG; GATA2; GATA1; } \\
\text { RELA; NFKB1 }\end{array}$ & 2.90E-11 & 4.66E-10 & -40.40 & 425.6891794 \\
\hline $\begin{array}{l}\text { HIF-1-alpha } \\
\text { transcription factor } \\
\text { network }\end{array}$ & $\begin{array}{l}\text { JUN; SMAD4; CREB1; } \\
\text { SMAD3; SP1; HNF4A; } \\
\text { EP300; ARNT; GATA2; ETS1; } \\
\text { HIF1A }\end{array}$ & $2.90 \mathrm{E}-11$ & 4.33E-10 & -40.40 & 425.6891794 \\
\hline $\begin{array}{l}\text { Direct p53 } \\
\text { effectors }\end{array}$ & $\begin{array}{l}\text { FOXA1; JUN; NFYA; VDR; } \\
\text { NFYC; HIC1; SMARCA4; } \\
\text { TFDP1; SP1; E2F1; EP300; } \\
\text { TP53; TP63; ATF3 }\end{array}$ & 4.65E-11 & $6.48 \mathrm{E}-10$ & -24.95 & 257.7948324 \\
\hline $\begin{array}{l}\text { Regulation of } \\
\text { Androgen receptor } \\
\text { activity }\end{array}$ & $\begin{array}{l}\text { AR; EGR1; JUN; HDAC1; } \\
\text { EP300; SRY; NR3C1; } \\
\text { NR2C2; GATA2 }\end{array}$ & 1.35E-09 & $1.76 \mathrm{E}-08$ & -41.95 & 372.1071412 \\
\hline $\begin{array}{l}\text { Signaling mediated } \\
\text { by p38-alpha and } \\
\text { p38-beta }\end{array}$ & $\begin{array}{l}\text { ATF1; CEBPB; JUN; CREB1; } \\
\text { MITF; HBP1; ESR1; TP53 }\end{array}$ & 2.19E-09 & $2.70 \mathrm{E}-08$ & -51.03 & 441.8400253 \\
\hline $\begin{array}{l}\text { p73 transcription } \\
\text { factor network }\end{array}$ & $\begin{array}{l}\text { YAP1; WT1; SP1; MYC; } \\
\text { HSF1; EP300; FOXO3; } \\
\text { GATA1; TP63; RELA }\end{array}$ & 3.39E-09 & 3.94E-08 & -31.07 & 263.1731164 \\
\hline $\begin{array}{l}\text { Calcineurin- } \\
\text { regulated NFAT- } \\
\text { dependent } \\
\text { transcription in } \\
\text { lymphocytes }\end{array}$ & $\begin{array}{l}\text { FOSL1; EGR1; JUN; IRF4; } \\
\text { E2F1; PPARG; GATA3; } \\
\text { FOXP3 }\end{array}$ & $1.10 \mathrm{E}-08$ & $1.21 \mathrm{E}-07$ & -42.15 & 335.5324137 \\
\hline $\begin{array}{l}\text { RXR and RAR } \\
\text { heterodimerization } \\
\text { with other nuclear } \\
\text { receptor }\end{array}$ & $\begin{array}{l}\text { SREBF1; NR4A1; VDR; } \\
\text { RARA; PPARG; PPARD }\end{array}$ & 7.93E-08 & 8.29E-07 & -60.59 & 430.2696264 \\
\hline $\begin{array}{l}\text { Notch signaling } \\
\text { pathway }\end{array}$ & $\begin{array}{l}\text { YY1; NCOR1; CCND1; } \\
\text { HDAC1; MYC; EP300; } \\
\text { GATA3; RBPJ }\end{array}$ & 8.39E-08 & 8.35E-07 & -32.86 & 232.5624802 \\
\hline $\begin{array}{l}\text { FOXA2 and FOXA3 } \\
\text { transcription factor } \\
\text { networks }\end{array}$ & $\begin{array}{l}\text { FOXA1; CEBPB; CREB1; } \\
\text { SP1; HNF4A; NR3C1; } \\
\text { FOXA2 }\end{array}$ & 2.09E-07 & 1.99E-06 & -37.70 & 251.8464888 \\
\hline $\begin{array}{l}\text { Presenilin action in } \\
\text { Notch and Wnt }\end{array}$ & $\begin{array}{l}\text { JUN; CCND1; HDAC1; MYC; } \\
\text { CTNNB1; RBPJ; PPARD }\end{array}$ & $2.45 \mathrm{E}-07$ & $2.22 \mathrm{E}-06$ & -36.88 & 243.8556084 \\
\hline
\end{tabular}




\begin{tabular}{|c|c|c|c|c|}
\hline $\begin{array}{l}\text { HIF-2-alpha } \\
\text { transcription factor } \\
\text { network }\end{array}$ & $\begin{array}{l}\text { SP1; EP300; ARNT; ETS1; } \\
\text { ELK1; POU5F1 }\end{array}$ & 7.32E-07 & $6.38 \mathrm{E}-06$ & -42.77 \\
\hline
\end{tabular}

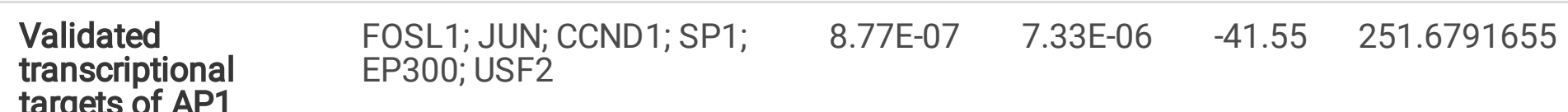
family members

Fra1 and Fra2

\begin{tabular}{llllll}
$\begin{array}{l}\text { ATF-2 transcription } \\
\text { factor network }\end{array}$ & JUN; CREB1; CCND1; & $1.25 \mathrm{E}-06$ & $1.00 \mathrm{E}-05$ & -29.25 & 172.697571 \\
\hline $\begin{array}{l}\text { FOXM1 } \\
\text { transcription factor } \\
\text { network }\end{array}$ & $\begin{array}{l}\text { CCND1; SP1; MYC; EP300; } \\
\text { FOXM1; ESR1 }\end{array}$ & $1.99 \mathrm{E}-06$ & $1.54 \mathrm{E}-05$ & -36.36 & 207.2522483 \\
& & & & &
\end{tabular}

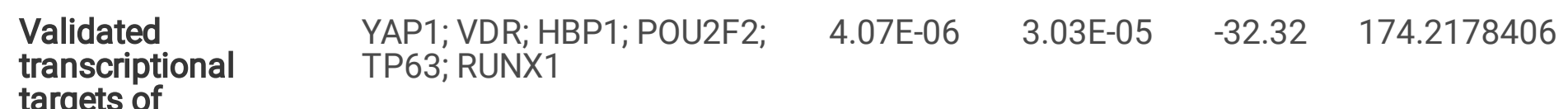
deltaNp63 isoforms

\begin{tabular}{llllll}
$\begin{array}{l}\text { IL6-mediated } \\
\text { signaling events }\end{array}$ & $\begin{array}{l}\text { CEBPB; JUN; MYC; IRF1; } \\
\text { STAT3; MITF }\end{array}$ & $4.64 \mathrm{E}-06$ & $3.34 \mathrm{E}-05$ & -31.61 & 168.6197375 \\
\hline $\begin{array}{l}\text { Validated } \\
\text { transcriptional } \\
\text { targets of TAp63 }\end{array}$ & TFAP2C; VDR; SP1; EP300; & 1.08E-05 & $7.50 \mathrm{E}-05$ & -27.44 & 136.3231851 \\
\hline & & & & &
\end{tabular}
targets of TAp63 isoforms

$\begin{array}{llllll}\begin{array}{l}\text { Signaling events } \\ \text { mediated by HDAC } \\ \text { Class II }\end{array} & \begin{array}{l}\text { BCOR; NR3C1; GATA2; } \\ \text { GATA1; ESR1 }\end{array} & 1.63 \mathrm{E}-05 & 1.10 \mathrm{E}-04 & -35.64 & 170.6272481 \\ & & & & \end{array}$
$\begin{array}{lllll}\text { IL2 signaling } \quad \text { MYC; E2F1; FOXO3; RELA; } & \text { 1.89E-05 } & 1.23 \mathrm{E}-04 & -34.63 & 163.549873\end{array}$ events mediated by NFKB1 PI3K

\begin{tabular}{llllll}
$\begin{array}{l}\text { BCR signaling } \\
\text { pathway }\end{array}$ & $\begin{array}{l}\text { JUN; POU2F2; ETS1; ELK1; } \\
\text { RELA; NFKB1 }\end{array}$ & $3.22 \mathrm{E}-05$ & $2.04 \mathrm{E}-04$ & -22.72 & 102.0670923 \\
\hline $\begin{array}{l}\text { Integrin-linked } \\
\text { kinase signaling }\end{array}$ & $\begin{array}{l}\text { JUN; ZEB1; CREB1; CCND1; } \\
\text { CTNNB1 }\end{array}$ & $6.59 \mathrm{E}-05$ & $4.05 \mathrm{E}-04$ & -26.93 & 112.6035437 \\
\hline $\begin{array}{l}\text { LKB1 signaling } \\
\text { events }\end{array}$ & $\begin{array}{l}\text { SMAD4; CREB1; MYC; } \\
\text { ESR1; TP53 }\end{array}$ & $8.15 \mathrm{E}-05$ & $4.86 \mathrm{E}-04$ & -25.78 & 105.4357932 \\
$\begin{array}{l}\text { Validated targets } \\
\text { of C-MYC } \\
\text { transcriptional } \\
\text { activation }\end{array}$ & $\begin{array}{l}\text { FOSL1; SMAD4; SMAD3; } \\
\text { MYC; EP300; TP53 }\end{array}$ & $1.06 \mathrm{E}-04$ & $6.17 \mathrm{E}-04$ & -18.41 & 73.15299554 \\
\hline
\end{tabular}

Retinoic acid receptors-mediated HDAC1; VDR; RARA; EP300 1.35E-04 7.63E-04 -34.63 133.9714725 signaling 
signaling

CD40/CD40L

signaling

Coregulation of Androgen receptor activity

IL4-mediated signaling events

Trk receptor signaling mediated by PI3K and PLCgamma

Downstream signaling in naive CD8+ $T$ cells

ErbB1 downstream signaling

Regulation of cytoplasmic and nuclear SMAD2/3 signaling

IFN-gamma pathway

Hypoxic and

oxygen

homeostasis regulation of HIF-1alpha

Angiopoietin receptor Tie2mediated signaling

EOMES; FOSL1; EGR1; JUN; ELK1

AR; CCND1; CTNNB1; TCF4; BRCA1

CEBPB; SPI1; IRF4; SP1; ETS1

EGR1; CREB1; CCND1;

FOXO3

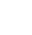

JUN; MYC; RELA; NFKB1

$1.78 \mathrm{E}-04 \quad 9.55 \mathrm{E}-04 \quad-32.32$

121.156723

2.42E-04

$0.001267-20.54$

74.26029048

$20.54 \quad 74.26029048$


Differentially expressed genes

literature coverage for selected keywords

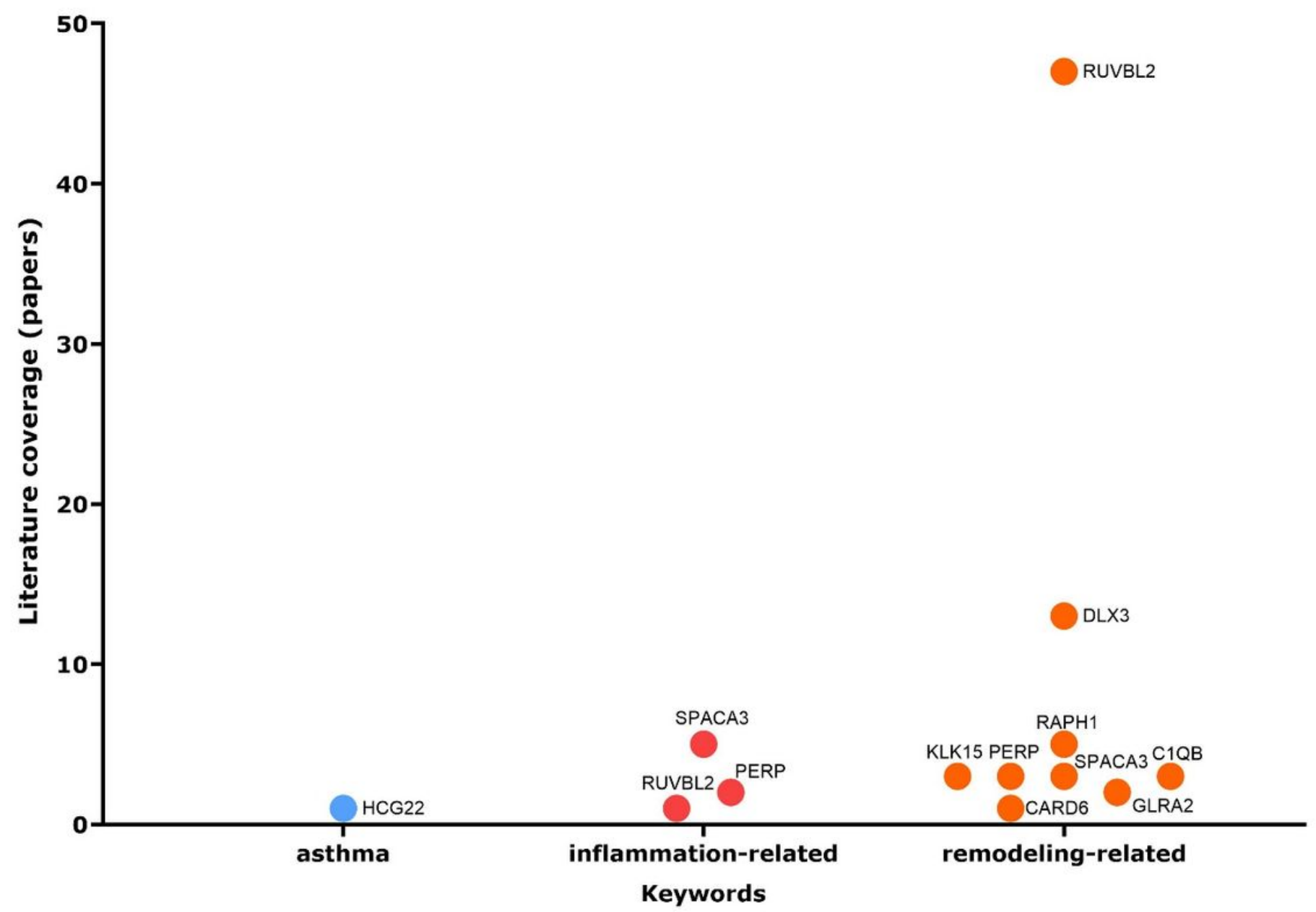

Figure 1

Literature coverage of differentially expressed genes for asthma, inflammation-related and remodelingrelated keywords. All p-values for differential expression $\geq 0.01$. Automated literature mining performed using GenClip 3.0. 
Differentially co-expressed genes

literature coverage for selected keywords

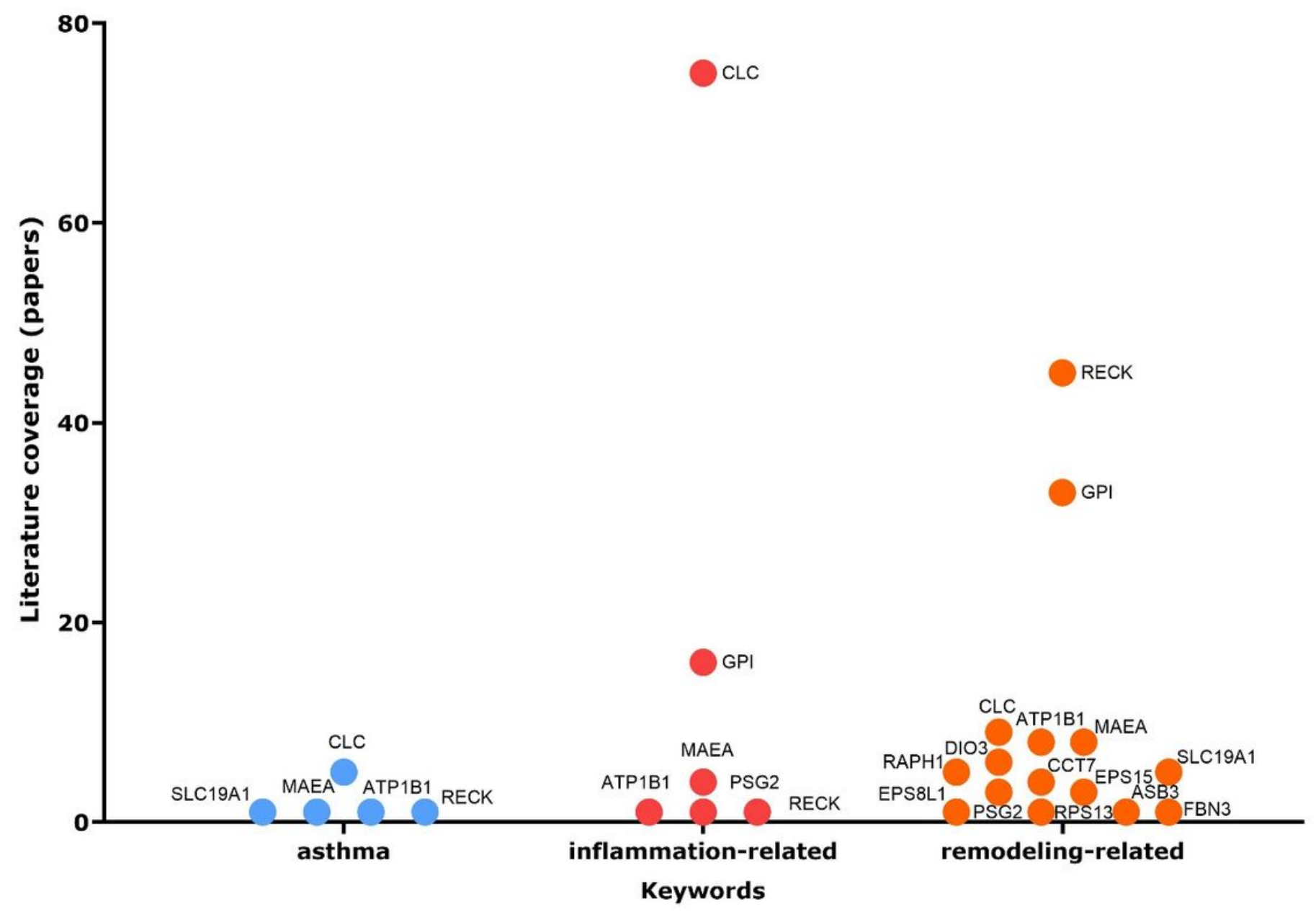

Figure 2

Literature coverage of differentially co-expressed genes for asthma, inflammation-related and remodelingrelated keywords. All $p$-values for differential expression $\geq 0.01$. Automated literature mining performed using GenClip 3.0. 
Non-eosinophilic asthma group

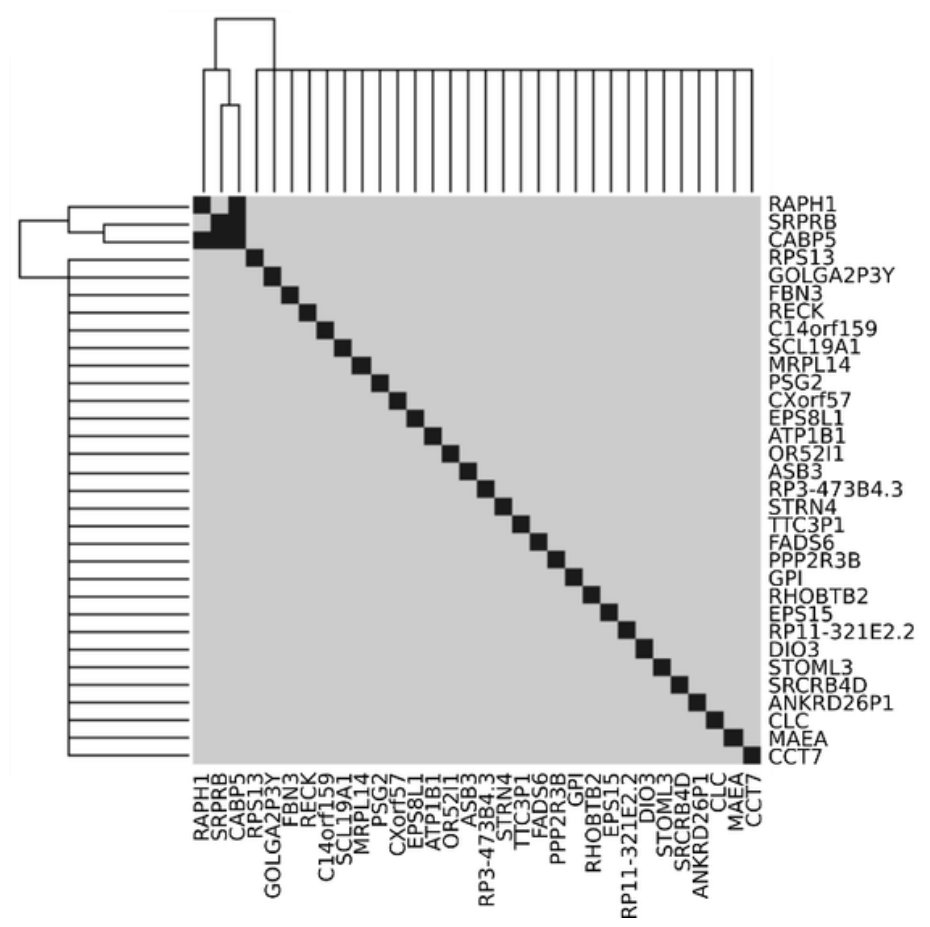

Eosinophilic asthma group

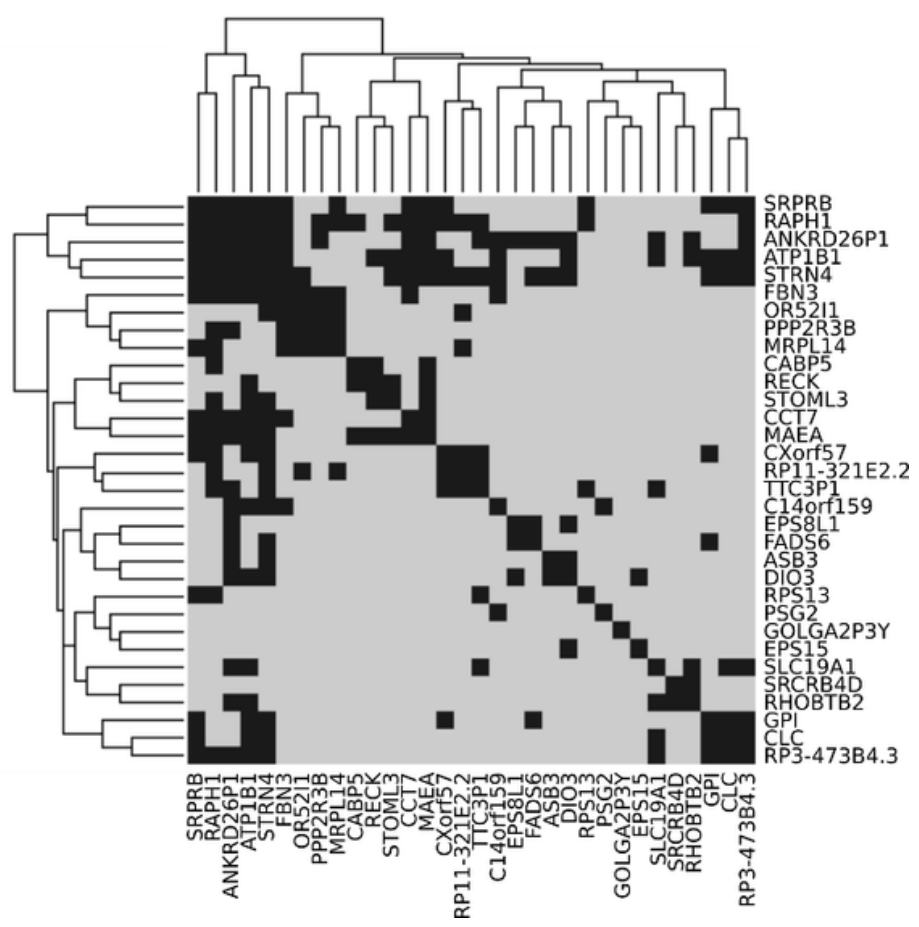

Figure 3

Structural patterns of gene differential co-expression (adjacency matrices). Black color indicates gene-gene correlation exceeding $r=0.8$. 


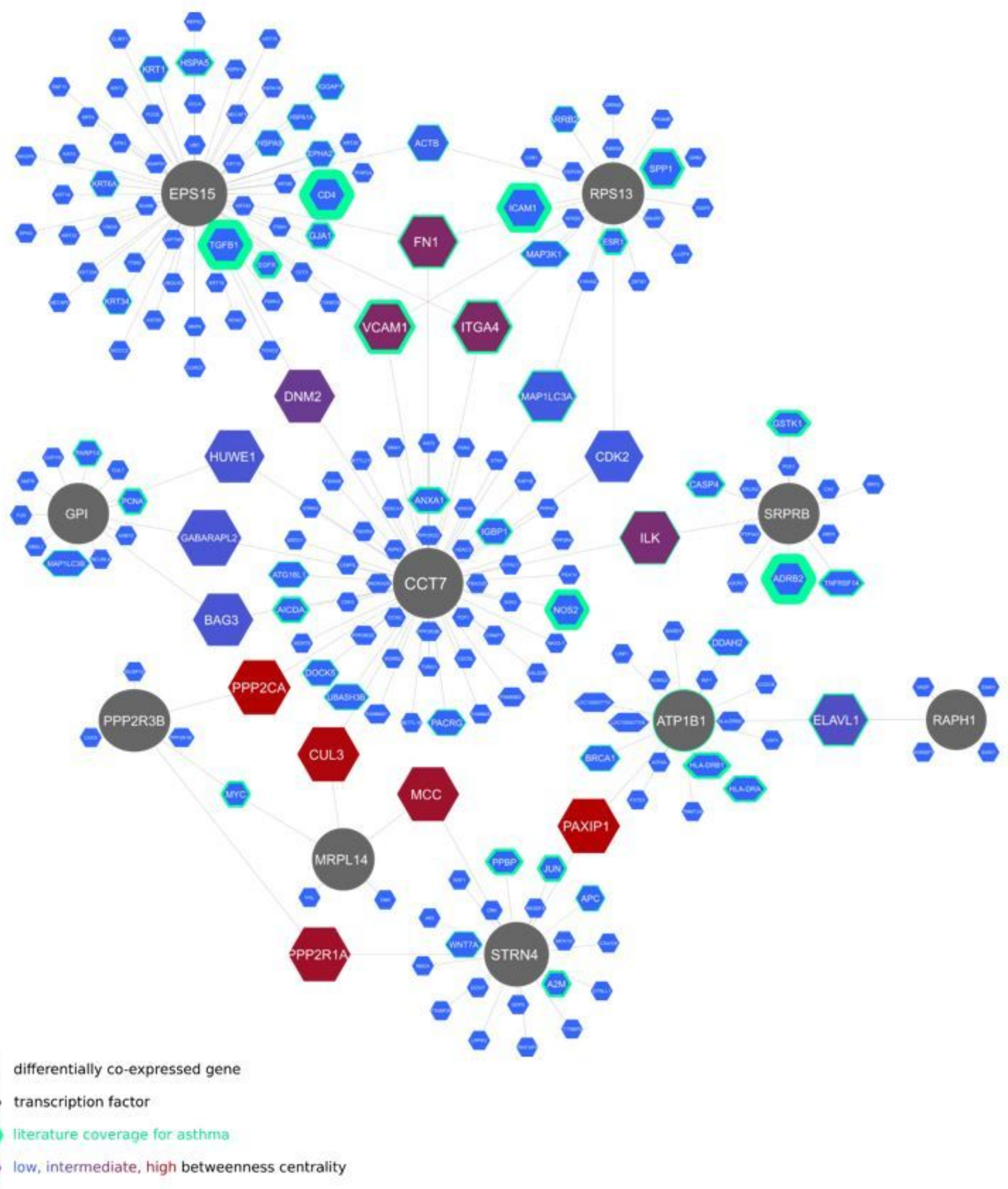

Figure 4

Lung-specific protein-protein interactions of genes differentially expressed between eosinophilic and noneosinophilic asthma patients in bronchial brush biopsy samples. Interactions retrieved from curated DifferentialNet database. 


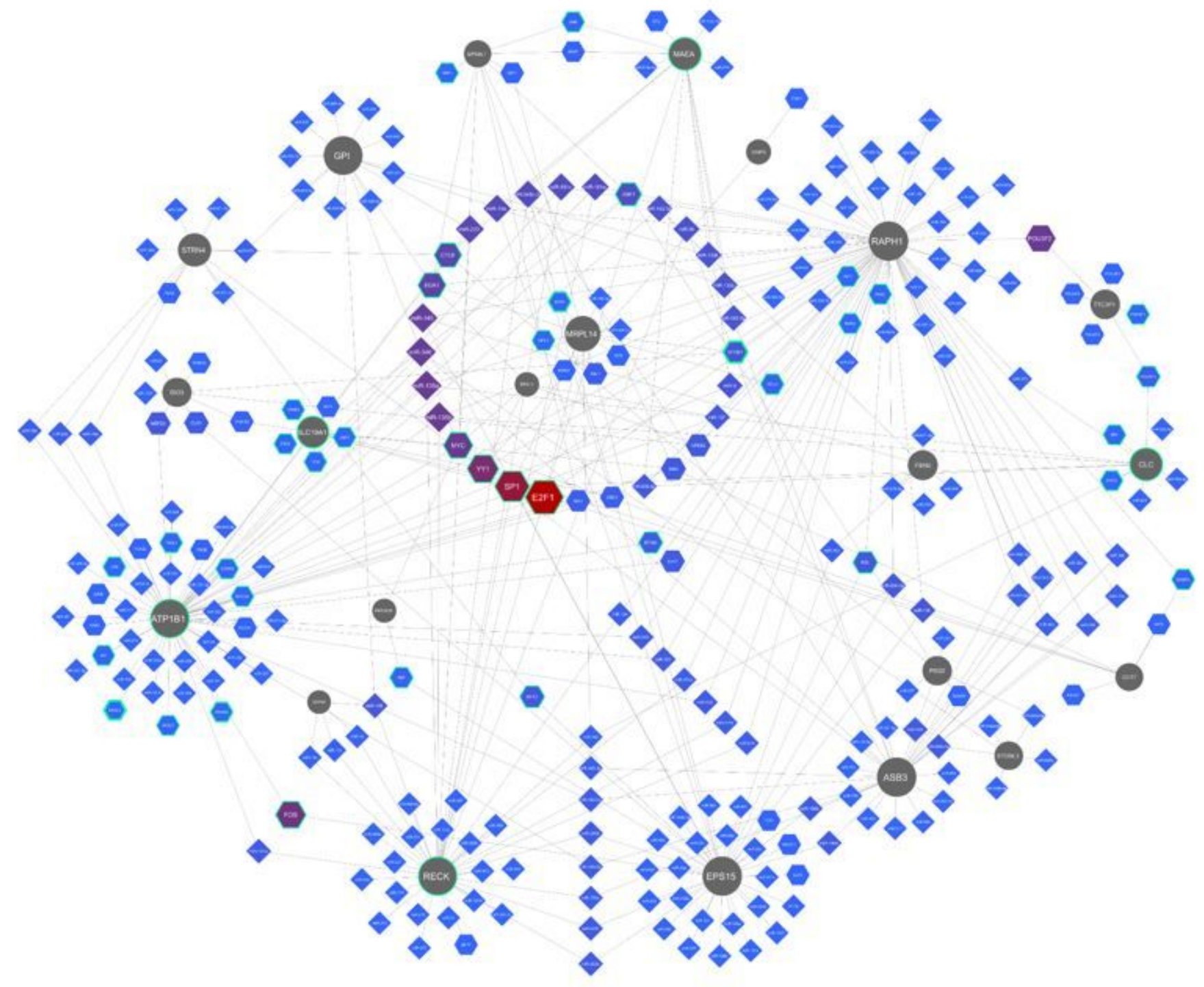

differentially co-expressed gene

transcription factor

micro-RNA

literature coverage for asthma

low, intermediate, high betweenness centrality

\section{Figure 5}

Coregulatory network of miRNA, transcription factors and genes differentially expressed between eosinophilic and non-eosinophilic asthma patients in bronchial brush biopsy samples. Interactions retrieved from the RegNetwork repository. 


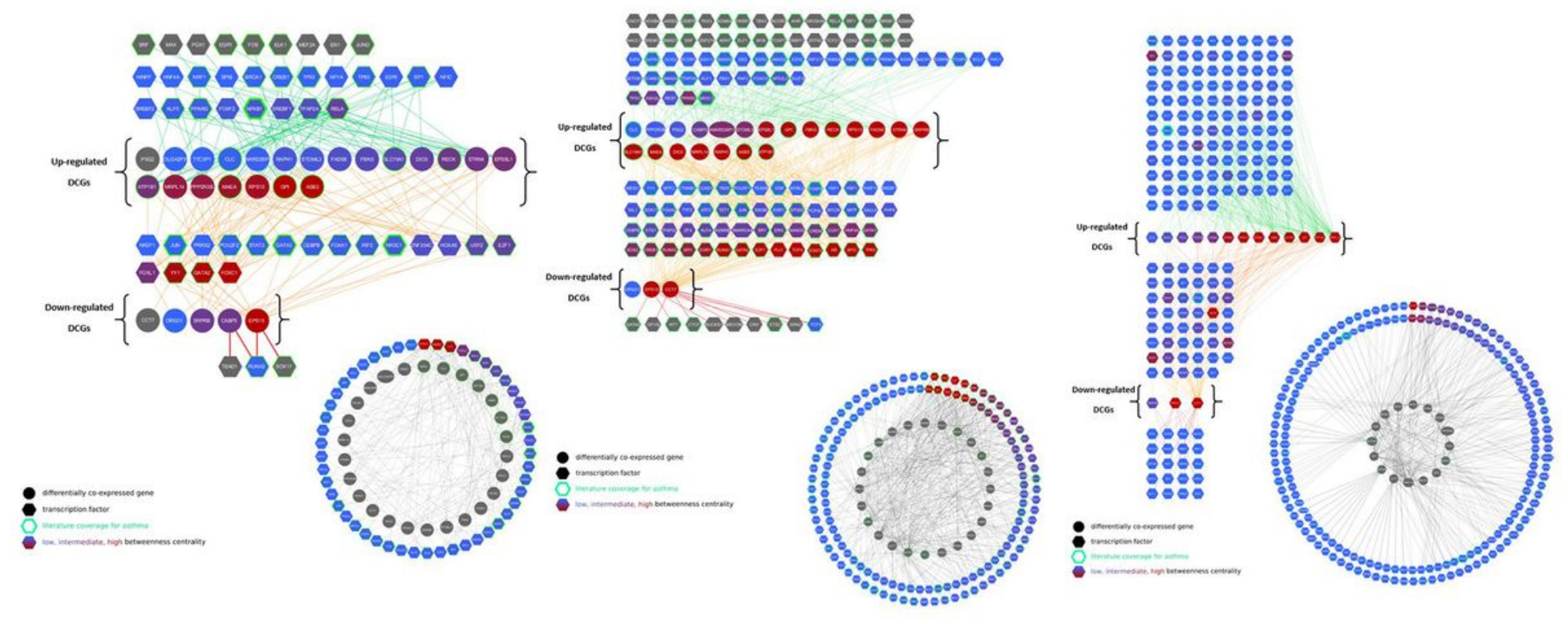

Figure 6

A. Gene regulatory network - transcription factor-gene interactions. Transcription factor targets database inferred from integrating literature curated JASPAR data. Green edges link to TFs targeting only DCGs upregulated in EA, orange edges to TFs targeting DCGs upregulated in both EA and non-EA, red edges - TFs targeting only DCGs upregulated in non-EA. B. Gene regulatory network - transcription factor-gene interactions. Transcription factor targets inferred from Chip-X curated database. C. Gene regulatory network - transcription factor-gene interactions. Transcription factor and gene target data derived from the ENCODE ChIP-seq data. Peak intensity signal $<500$, predicted regulatory potential score $<1$ (BETA minus algorithm). 
literature coverage for asthma vs. betweenness centrality in TF-DCG regulatory network

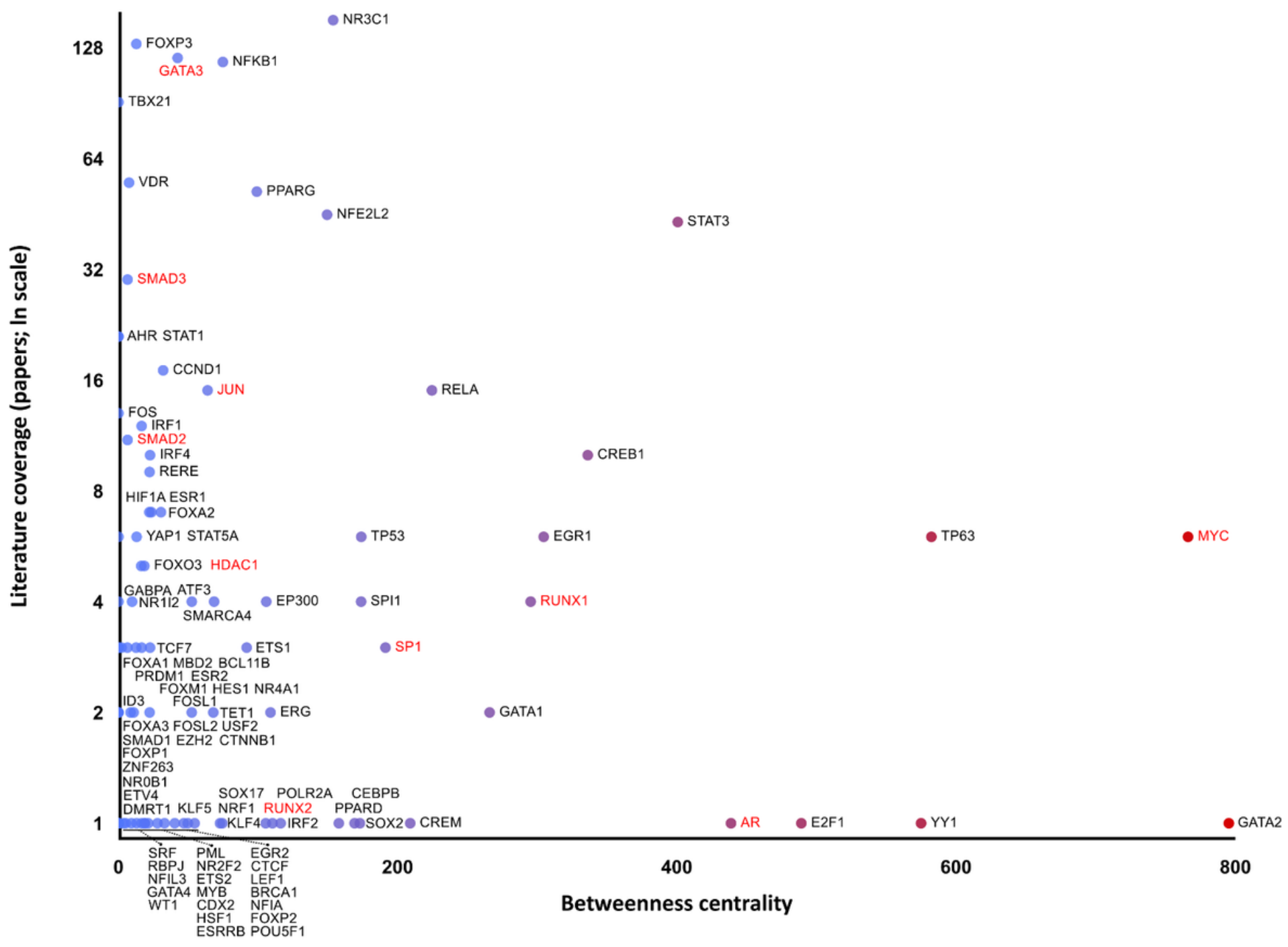

Figure 7

Literature coverage for asthma against betweenness centrality in transcription factor-differentially coexpressed genes. Transcription factors combined from Figures 6A-C. Genes labeled in red form the SMAD2/3 signaling pathway. 